\title{
Near-surface soil moisture assimilation for quantifying effective soil hydraulic properties using genetic algorithms: 2. Using airborne remote sensing during SGP97 and SMEX02
}

\author{
Amor V. M. Ines ${ }^{1,2}$ and Binayak P. Mohanty ${ }^{1}$ \\ Received 24 March 2008; revised 6 August 2008; accepted 20 August 2008; published 9 January 2009.
}

[1] Pixel-based effective soil hydraulic parameters are crucial inputs for large-scale hydroclimatic modeling. In this paper, we extend/apply a genetic algorithm (GA) approach for estimating these parameters at the scale of an airborne remote sensing (RS) footprint. To estimate these parameters, we used a time series of near-surface RS soil moisture data to invert a physically based soil-water-atmosphere-plant (SWAP) model with a (multipopulated) modified-microGA. Uncertainties in the solutions were examined in two ways: (1) by solving the inverse problem under various combinations of modeling conditions in a respective way; and (2) the same as the first method but the inverse solutions were determined in a collective way aimed at finding the robust solutions for all the modeling conditions (ensembles). A cross validation of the derived soil hydraulic parameters was done to check their effectiveness for all the modeling conditions used. For our case studies, we considered three electronically scanned thinned array radiometer (ESTAR) footprints in Oklahoma and four polarimetric scanning radiometer (PSR) footprints in Iowa during the Southern Great Plains 1997 (SGP97) Hydrology Experiment and Soil Moisture Experiment 2002 (SMEX02) campaigns, respectively. The results clearly showed the promising potentials of near-surface RS soil moisture data combined with inverse modeling for determining average soil hydrologic properties at the footprint scale. Our cross validation showed that parameters derived by method 1 under water table (bottom boundary) conditions are applicable also for free-draining conditions. However, parameters derived under free-draining conditions generally produced too wet near-surface soil moisture when applied under water table conditions. Method 2, on the other hand, produced robust parameter sets applicable for all modeling conditions used. These results were validated using distributed in situ soil moisture and soil hydraulic properties measurements, and texture-based data from the UNSODA database. In this study, we conclude that inverse modeling of RS soil moisture data is a promising approach for parameter estimation at large measurement support scale. Nevertheless, the derived effective soil hydraulic parameters are subject to the uncertainties of remotely sensed soil moisture data and from the assumptions used in the soil-water-atmosphereplant modeling. Method 2 provides a flexible framework for accounting these sources of uncertainties in the inverse estimation of large-scale soil hydraulic properties. We have illustrated this flexibility by combining multiple data sources and various modeling conditions in our large-scale inverse modeling.

Citation: Ines, A. V. M., and B. P. Mohanty (2009), Near-surface soil moisture assimilation for quantifying effective soil hydraulic properties using genetic algorithms: 2. Using airborne remote sensing during SGP97 and SMEX02, Water Resour. Res., 45, W01408, doi:10.1029/2008WR007022.

\section{Introduction}

[2] In recent years, remote sensing (RS) has proved to be a promising method for measuring soil moisture at the regional or larger scale. Compared with carefully designed,

\footnotetext{
${ }^{1}$ Department of Biological and Agricultural Engineering, Texas A\&M University, College Station, Texas, USA.

${ }^{2}$ Now at International Research Institute for Climate and Society, The Earth Institute at Columbia University, Palisades, New York, USA.

Copyright 2009 by the American Geophysical Union. 0043-1397/09/2008WR007022
}

large-scale in situ measurements, RS is by far the fastest and most effective way of conducting soil moisture measurements at such a spatial scale [Jackson, 1993; Njoku and Entekhabi, 1996; Schmugge, 1998; Schmugge et al., 2002]. There are, however, some inherent limitations of remotely sensed soil moisture, including the relatively shallow observation depths $(\sim 0-5 \mathrm{~cm})$ [Jackson et al., 1995] and coarse spatial resolutions of satellite-based remote sensing [Njoku et al., 2003; Crow et al., 2005; Das and Mohanty, 2006]. Notwithstanding these limitations, a variety of methods of integrating RS soil moisture data with dynamic soilvegetation-atmosphere-transfer (SVAT) models have been 
proposed to advance the use of RS soil moisture in various hydroclimatic applications [e.g., Jackson, 1993; Kostov and Jackson, 1993; Entekhabi et al., 1994]. Most of the previous studies were aimed at using near-surface RS soil moisture data to retrieve root zone soil moisture required for initializing SVAT applications [e.g., Walker et al., 2001; Crow and Wood, 2003; Dunne and Entekhabi, 2005].

[3] In recent literature, direct data assimilation and Kalman filtering of observed near-surface RS soil moisture data have been used to condition/update (off-line) the simulated soil moisture profiles in vadose zone modeling [e.g., Walker et al., 2001; Reichle et al., 2001; Margulis et al., 2002; Crow and Wood, 2003; Heathman et al., 2003; Das and Mohanty, 2006]. The results of these soil moisture data assimilation studies have been generally promising, but when a significant disparity between the assimilated and validation soil moisture data is apparent, the bias is often attributed to uncertainties of the hydrological/constitutive models, and the input data/parameters used, e.g., the soil hydraulic parameters [Das and Mohanty, 2006]. Assuming that the physically based models used are appropriate, then the major issue boils down to the problem of scale-dependent model parameters that are effective at that particular spatial scale. The question is, What should be the appropriate values of the soil hydraulic parameters on a particular spatial scale, and how can they be determined [Mohanty and Zhu, 2007]? In an RS pixel, we generally expect a mixture of features, e.g., soil types, vegetation attributes, topographic features, land management practices, etc., and the soil moisture dynamics in this control volume is governed by the interrelationships among these features and their responses to different environmental and climatic forcings [Mohanty et al., 2000; Mohanty and Skaggs, 2001]. In large-scale hydrologic modeling, the concept of "effective parameters" has been proposed to account for the heterogeneities in the pixel/grid scale [Feddes et al., 1993a, 1993b; Wood, 1994]. The effective soil hydraulic parameters can be viewed as a representative set of parameters that characterizes an equivalent homogenous land unit in lieu of the real-world domain. Thus, when used in model application it can approximate the mean of the ensemble flux at that particular pixel derived from fully distributed/stochastic simulations, or the mean flux from RS data in actual measurements. Two methods are commonly used in defining these effective parameters: a bottom-up approach where the point-scale soil hydraulic parameters are aggregated/ averaged into the scale of application, and a top-down approach where the measurements of a state variable, e.g., near-surface soil moisture or evapotranspiration (ET) from RS observations, at that particular scale are used as conditioning criteria to define these parameters using inverse modeling (IM). The bottom-up approach evolved from the similar media scaling of Miller and Miller [1956]. Recent studies of Zhu and Mohanty [2002, 2003, 2004], Zhu et al. [2004], and Mohanty and Zhu [2007] (see also B. P. Mohanty, unpublished data, 2006, http://vadosezone. tamu.edu) attempted to establish guidelines for defining these effective soil hydraulic parameters at various hydrological conditions. The difficulty of the bottom-up approach is the need for a large number of point scale soil hydraulic parameters across a spatial domain, which are not always available and very expensive and time-consuming to establish in real-world conditions. Furthermore, bottom-up approaches need appropriate aggregation techniques for averaging soil hydraulic parameters based on prevailing hydroclimatic conditions as shown in the previous studies. In contrast, the top-down approach is simpler and is a promising alternative for estimating large-scale soil hydrologic properties, as the state variable is measured from a remote sensing platform, and hence it can encompass large areas (measurement support) for analysis. It is noteworthy that a priori knowledge of soil classes in the RS pixel is not a prerequisite for the top-down approach, as a wide range of soils can be prescribed as a global search space for the inverse analyses [Feddes et al., 1993a, 1993b]. However, if limited footprint soil moisture (temporal) data are available for inverse modeling, a priori information of the ranges of footprint soil hydraulic parameters may be advisable.

[4] In this paper, following the work Ines and Mohanty [2008a] on inverse modeling of near-surface soil moisture with a genetic algorithm (GA) at the local scale, we present our study on large-scale inverse modeling of near-surface (airborne) remote sensing soil moisture data during the Southern Great Plains 1997 (SGP97) [Jackson et al., 1999] and Soil Moisture Experiment 2002 (SMEX02) [Cosh et al., 2004] hydrology campaigns in Oklahoma and Iowa, respectively. We also present a flexible framework for addressing sources of uncertainties (data/modeling errors) in the inverse modeling of large-scale near-surface soil moisture from a GA perspective.

\section{Materials and Methods}

\subsection{Near-Surface Soil Moisture Assimilation}

[5] The main hypothesis used in this study is that nearsurface RS soil moisture data contain useful information that can describe the effective hydrologic conditions of a pixel such that when appropriately inverted would provide a set of soil hydraulic parameters representative of that pixel. To derive these footprint effective parameters, we explored the top-down approach described by Ines and Mohanty [2008a] for quantifying effective soil hydraulic parameters in the soil profile, in which a multipopulated modifiedmicro genetic algorithm (GA) [Ines and Droogers, 2002a; Ines and Honda, 2005] (see also http://www.cuaerospace.$\mathrm{com} /$ carroll/ga.html) is coupled with a physically based soilwater-atmosphere-plant (SWAP) model [Van Dam et al., 1997] and used in the inverse estimation of soil hydraulic parameters using mainly time series of near-surface soil moisture as conditioning data. A multipopulated modifiedmicroGA uses multiple populations to explore the search space of the inverse problem [Ines and Mohanty, 2008a; Krishnakumar, 1989] (see also http://www.cuaerospace.com/carroll/ga.html). The main contribution of this paper is the further improvements of the methodology [Ines and Mohanty, 2008a] for large-scale parameter estimation applications using soil moisture data from airborne remote sensing.

[6] SWAP is a 1-D variably saturated flow model that solves the Richards equation to simulate the soil moisture dynamics in a vertical soil column. The model uses the Mualem-Van Genuchten equations [Van Genuchten, 1980; 


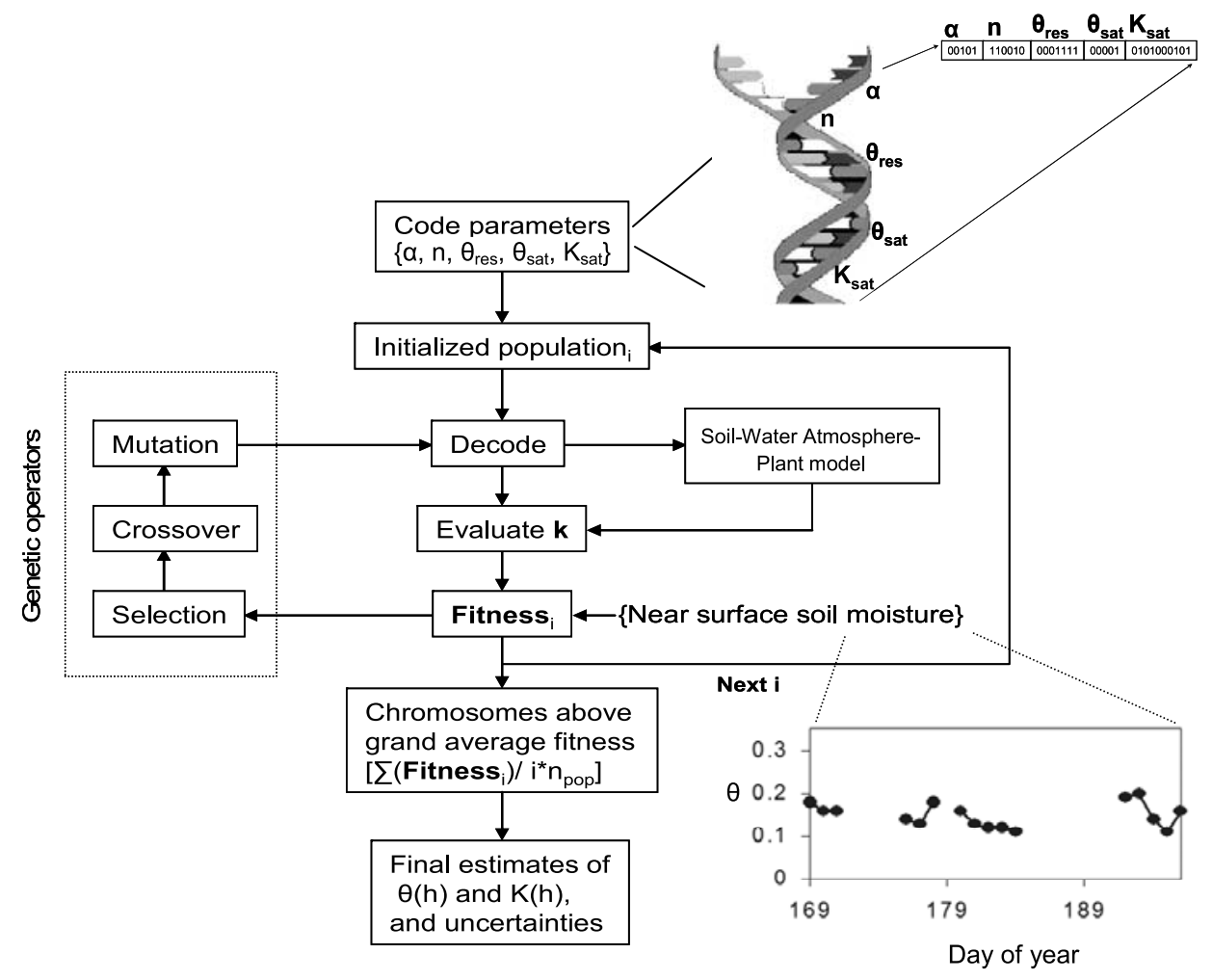

Figure 1. Schematic diagram of the inverse modeling-based near-surface soil moisture assimilation using a multipopulated genetic algorithm [Ines and Mohanty, 2008a, 2008b].

Mualem, 1976] to define the hydraulic properties of soil in the control volume:

$$
\begin{gathered}
S_{e}=\frac{\theta(h)-\theta_{\text {res }}}{\theta_{\text {sat }}-\theta_{\text {res }}}=\left[\frac{1}{1+|\alpha h|^{n}}\right]^{m} \\
K(h)=K_{\text {sat }} S_{e}^{\lambda}\left[1-\left(1-S_{e}^{1 / m}\right)^{m}\right]^{2} .
\end{gathered}
$$

[7] To evaluate equation (1) and (2), parameters $\alpha, n, \theta_{\text {res }}$, $\theta_{\text {sat }}, K_{\text {sat }}$, and $\lambda$, which are soil specific, must be determined beforehand. At the scale of the airborne remote sensing footprint, they are more perceived as effective (resultant) parameters accounting for horizontal and vertical heterogeneity in the soil hydrologic unit. The pore-scale definitions of these parameters are given as follows: $\alpha\left(\mathrm{cm}^{-1}\right)$ is a shape parameter equivalent to the inverse of the bubbling pressure; $n()$ is a shape parameter that accounts for the pore size distribution; $\theta_{\text {res }}\left(\mathrm{cm}^{3} \mathrm{~cm}^{-3}\right)$ and $\theta_{\text {sat }}\left(\mathrm{cm}^{3} \mathrm{~cm}^{-3}\right)$ are the residual and saturated soil moisture content respectively; $K_{\text {sat }}\left(\mathrm{cm} \mathrm{d}^{-1}\right)$ is the saturated hydraulic conductivity; and $\lambda(\mathrm{)}$ is a shape parameter that accounts for tortuosity in the soil. On average, $\lambda$ is assumed to have a value of 0.5 [Mualem, 1976]; Van Genuchten [1980] proposed $m$ to be equal to $1-1 / n ; S_{e}$ ( ) is the relative saturation and $h$ is the pressure head $(-\mathrm{cm})$.

[8] SWAP considers the time-dependent top boundary conditions in terms of either a flux or given head, controlled dynamically based on a given set of nested criteria [Van Dam et al., 1997] related to the atmospheric forcings and hydrologic conditions at the soil surface. The bottom boundary condition can posed in various forms, e.g.,
Dirichlet, Neumann, or Cauchy type. The model is an integrated water management tool containing irrigation and drainage modules as well as process-based crop growth models for simulating the impacts of weather, soil type, plant type, and water management practices on the growth and development of the crops [Van Dam, 2000].

[9] The role of the genetic algorithm (GA) in inverse modeling is to search for the effective parameters at the footprint scale, while SWAP (parameterized at this scale) is used to evaluate the proposed parameter sets to test their suitability against a set criteria, e.g., reproducing the regional fluxes/near-surface soil moisture in the pixel. GAs are powerful techniques for solving complex problems in hydrological and water resources systems [e.g., Wang, 1991; Cieniawski et al., 1995; Ritzel et al., 1994; Oliveira and Loucks, 1997; Wardlaw and Sharif, 1999; Chan-Hilton and Culver, 2000; Wu et al., 2006; Gwo, 2001; Vrugt et al., 2001; Ines and Droogers, 2002a, 2002b; Ines et al., 2006]. A recent review of GA applications in hydrologic sciences is given by Savic and Khu [2005]. For completeness, we describe briefly the mechanics of GA in this section. Genetic algorithms combine the survival of the fittest mechanism with a structured but randomized information exchange to search for solutions of complex search/ optimization problems [Holland, 1975; Goldberg, 1989]. The search spaces of the unknown parameters, e.g., the soil hydraulic parameters, are discretized into finite lengths then coded as sets of binary (zeros and ones) substrings (in binary GA) laid out to form string structures called chromosomes. The arrangement of bits within a chromosome is a possible solution of the problem. First, a population of chromosomes is randomly generated as a starting position 


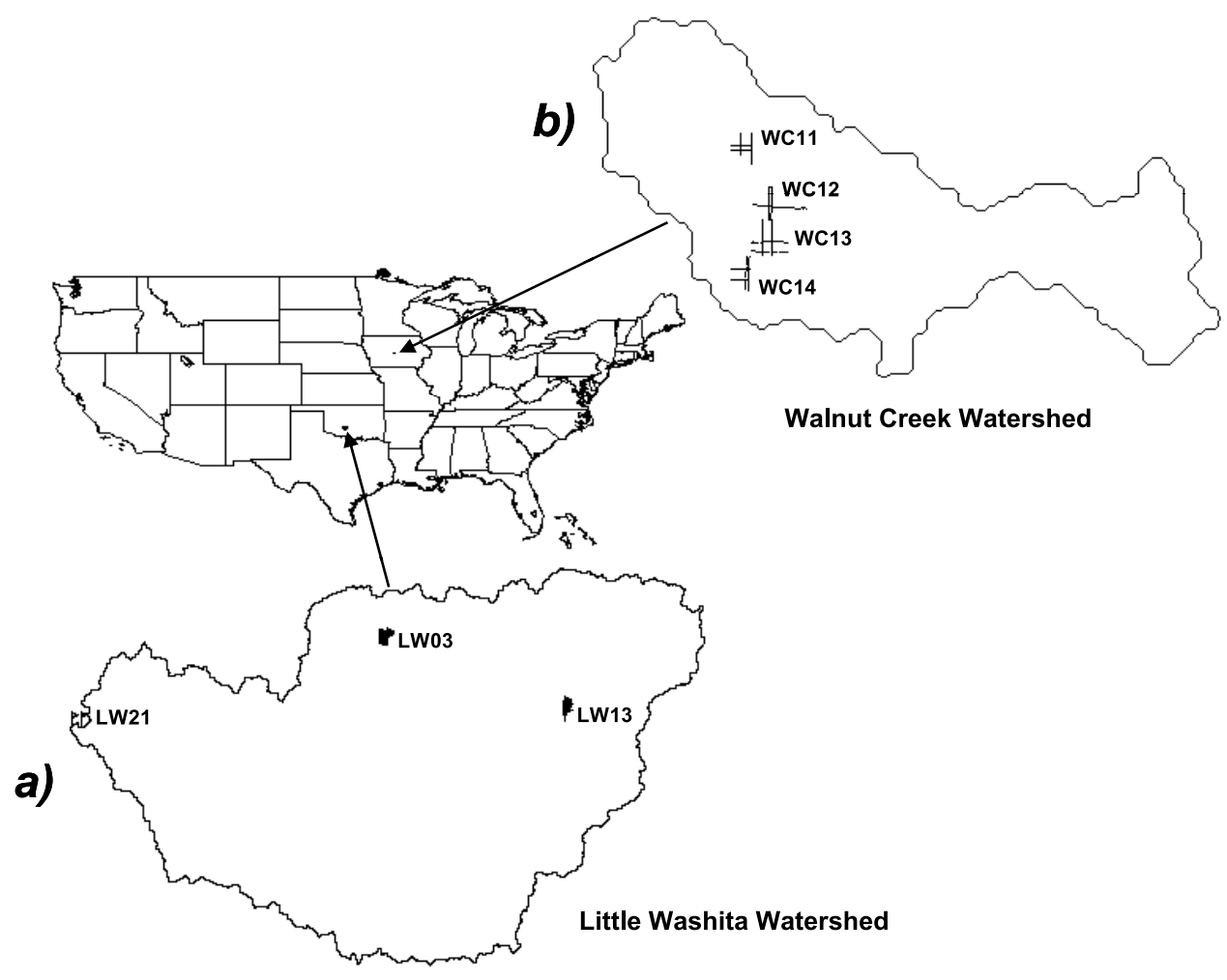

Figure 2. Locations of the selected fields in (a) Southern Great Plains 1997 (SGP97) (Oklahoma) and (b) Soil Moisture Experiment 2002 (SMEX02) (Iowa) sites.

for the search. The chromosomes are individually evaluated (here SWAP is invoked) to determine their suitability based on a prescribed fitness function. Then they undergo the process of selection, crossover, and mutation. On the basis of their fitness, they compete to be selected, mate, and reproduce for the next generation. During selection, the fitter chromosomes survive and the weaker die. The winning chromosomes randomly mate to exchange genetic information by the process of crossover (to produce offspring). The new chromosomes (offspring) are subjected to mutation to infuse fresh genetic materials for the new generations and to restore certain genetic characteristics that were lost due to degeneracy. The processes of selection, crossover, and mutation are repeated for many generations until the best possible solution (fittest chromosome) is achieved. Detailed descriptions of GA are given by Goldberg [1989] and Michalewicz [1996]. Figure 1 shows a schematic of the inverse modeling-based near-surface soil moisture assimilation using a multipopulated GA, in which the final solutions are derived from those chromosomes (in each population) whose fitness is above the grand average fitness of the all the chromosomes [see Ines and Mohanty, 2008a].

[10] As one of our goals is incorporating sources of uncertainties (e.g., data and modeling errors) in our regional inverse modeling, we implemented two major approaches to address this issue:

[11] 1. We used a modified-microGA in solving multiple modeling conditions (i.e., combinations of initial and bottom boundary conditions), respectively. If we define $\boldsymbol{k}$ as a variable representing Mualem-Van Genucthen parameters and $\boldsymbol{p}$ as elements of $\boldsymbol{k}$, then $\boldsymbol{k}=\{\boldsymbol{p}\}$ where $\boldsymbol{p}=\left\{\alpha, n, \theta_{\text {res }}\right.$, $\left.\theta_{\text {sat }}, K_{\text {sat }}, \lambda\right\}$. If $\lambda$ is fixed to a value of 0.5 [Mualem, 1976], then we can define $\boldsymbol{k}=\left\{\boldsymbol{p}_{i=1, \ldots, m-1}, \lambda\right\}$ where $i$ is the index of parameter position in the GA chromosome and $m$ is the total number of soil hydraulic parameters (here $m=6$ ). The objective is to minimize the absolute difference $Z(\boldsymbol{k})$ between the observed RS near-surface soil moisture $\hat{\theta}(t)$ and the simulated near-surface soil moisture $\theta(\boldsymbol{k}, \mathrm{t})$ across time $t$ (equation (3)), where $j$ is the index of modeling conditions, $t$ is the running index for time, and $N$ is the time duration.

$$
\operatorname{Minimize}\{Z(\boldsymbol{k})\}=\frac{1}{N} \sum_{t=1}^{N}|\theta(\boldsymbol{k}, t)-\hat{\theta}(t)|_{j} \quad \forall j
$$

[12] We define the fitness of the chromosome $\boldsymbol{p}$ ' (short for $\boldsymbol{p}_{i=1, \ldots, m-1}$ ) in equation (4) which is used by GA to test the suitability of $\boldsymbol{p}^{\prime}$ :

$$
\operatorname{fitness}\left(\boldsymbol{p}^{\prime}\right)_{j}=\frac{1}{\frac{1}{N} \sum_{t=1}^{N}|\theta(\boldsymbol{k}, t)-\hat{\theta}(t)|_{j}} \quad \forall j
$$

[13] 2. We used a modified-microGA in solving multiple modeling conditions collectively analogous to how a noisy GA [Miller, 1997; Smalley et al., 2000; Wu et al., 2006] 

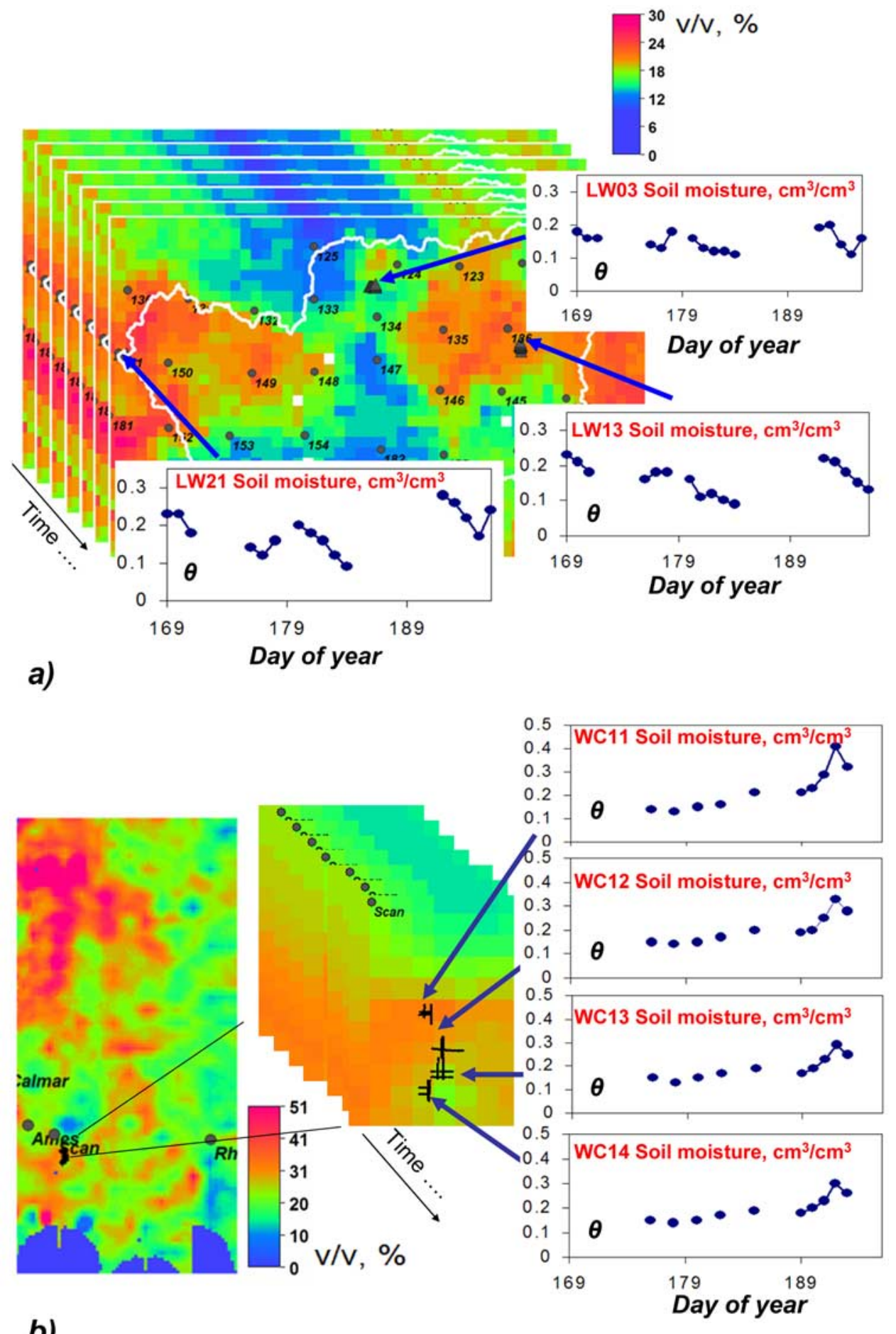

b)

Figure 3. Airborne remote sensing (RS) soil moisture data: (a) Electronically Scanned Thin Array Radiometer (ESTAR) (Little Washita (LW) fields) and (b) Polarimetric Scanning Radiometer (PSR) (Walnut Creek (WC) fields).

evolves a robust chromosome effective for many modeling conditions. The objective is to minimize the overall absolute difference $Z(\boldsymbol{k})$ between the observed RS near-surface soil moisture $\hat{\theta}(t)$ and the simulated near-surface soil moisture $\theta(\boldsymbol{k}, t)$ across time $t$ (equation (5)) for all the modeling conditions $j ; M$ is the total number of modeling conditions used.

$$
\operatorname{Minimize}\{Z(\boldsymbol{k})\}=\frac{1}{M} \sum_{j=1}^{M}\left[\frac{1}{N} \sum_{t=1}^{N}|\theta(\boldsymbol{k}, t)-\hat{\theta}(t)|\right]_{j}
$$


Table 1. Representations of the Mualem-Van Genuchten Parameters in the Genetic Algorithm ${ }^{\mathrm{a}}$

\begin{tabular}{lcccc}
\hline & \multicolumn{2}{c}{ Search Space } & & \\
\cline { 2 - 3 } \multicolumn{1}{c}{ Parameter } & $\begin{array}{c}\text { Minimum } \\
\text { Values }\end{array}$ & $\begin{array}{c}\text { Maximum } \\
\text { Values }\end{array}$ & Number of Bits $(L)$ & $2^{L}$ \\
\hline$\alpha\left(\mathrm{cm}^{-1}\right)$ & 0.0060 & 0.0330 & 5 & 32 \\
$n()$ & 1.200 & 1.610 & 6 & 64 \\
$\theta_{\text {res }}\left(\mathrm{cm}^{3} \mathrm{~cm}^{-3}\right)$ & 0.061 & 0.163 & 7 & 128 \\
$\theta_{\text {sat }}\left(\mathrm{cm}^{3} \mathrm{~cm}^{-3}\right)$ & 0.37 & 0.55 & 5 & 32 \\
$K_{\text {sat }}\left(\mathrm{cm} \mathrm{d}^{-1}\right)$ & 1.84 & 55.7 & 10 & 1024 \\
\hline
\end{tabular}

${ }^{\mathrm{a}}$ From Ines and Mohanty [2008a]. Global search space $=32 \times 64 \times 128 \times$ $32 \times 1024=8,589,934,592$. Example of $\boldsymbol{k}=\left\{\alpha, n, \theta_{\text {res }}, \theta_{\text {sat }}, K_{\text {sat }}\right\}=$ $\{001011100100001111000010101000101\}$. Probability of crossover $=$ 0.5 ; probability of creep mutation $=0.5$; probability of intermittent jump mutation $=0.05$; population $=10$ chromosomes; number of multipopulation $=3$; maximum generation $=500$.

[14] We define the sampling fitness (Sfitness) of the chromosome $\boldsymbol{p}$ ' in equation (6), which is used by GA to measure the suitability of the chromosome in method 2:

$$
\operatorname{Sfitness}\left(\boldsymbol{p}^{\prime}\right)=\frac{1}{M} \sum_{j=1}^{M} \text { fitness }\left(\boldsymbol{p}^{\prime}\right)_{j} \text {. }
$$

[15] The actual near-surface RS soil moisture data are already corrupted with errors (e.g., sensor/calibration errors, etc.), and hence the regional inverse modeling cannot explicitly account for the data errors in the solution. To demonstrate the capability of method 2 to account for data errors more explicitly, we applied it using multiple sources of data analogous to using various data sets from different airborne sensors/replicates. In this part of the study, we used airborne RS and regional in situ soil moisture data as our sources of replicates. In reality, regional in situ soil moisture data are not always available, but data from other airborne RS sensors might be available for this purpose. We can also perturb the available RS data based on its documented accuracy. With multidata analysis, the chromosome suitability is evaluated against the multiple data available in addition to the ensemble of modeling conditions as described above. In this paper, we call this approach method 2 with multidata analysis.

[16] The objective of method 2 with multidata analysis is to minimize the overall absolute difference $Z(\boldsymbol{k})$ between the observed RS near-surface soil moisture $\theta(t)$ and the simulated near-surface soil moisture $\theta(\boldsymbol{k}, t)$ across time $t$ (equation (7)) for all modeling conditions $j$ and for all data sources $r ; R$ is the total number of data sources/replicates:

$$
\operatorname{Minimize}\{Z(\boldsymbol{k})\}=\sum_{r=1}^{R}\left\{\frac{1}{M} \sum_{j=1}^{M}\left[\frac{1}{N} \sum_{t=1}^{N}|\theta(\boldsymbol{k}, t)-\hat{\theta}(t)|\right]_{j}\right\}_{r}
$$

[17] Here we define the sampling fitness (Sfitness) of the chromosome $\boldsymbol{p}$ ' as in equation (8). Each data source $r$ can be weighted (deterministic/stochastic) with $\omega_{r}$ so that data with lesser errors (higher quality) can be given more significance in the inverse modeling, and vice versa (equation (8)). Here we used a deterministic approach to weighting the data sources in which both sources have equal weights or contributions to the sampling fitness:

$$
\operatorname{Sfitness}\left(\boldsymbol{p}^{\prime}\right)=\sum_{r=1}^{R}\left\{\omega_{r} \times \frac{1}{M} \sum_{j=1}^{M} \text { fitness }\left(\boldsymbol{p}^{\prime}\right)_{j}\right\}_{r} .
$$

[18] The uncertainties of top boundary conditions (e.g., precipitation forcing) are equally important to be included in the estimation of soil hydraulic properties at the footprint scale [e.g., Peters-Lidard et al., 2008]. Methods 1 and 2 are flexible to account for the uncertainties in rainfall measurements (e.g., using multiple station rainfall data and/or from radar measurements). In this study, we assumed that the observed rainfall data used are representative of the airbone RS footprints (see section 2.2.1). Furthermore, method 2 (see equation (7)) can be generalized to include other sources of uncertainties in inputs, parameters (soil hydraulics/root water uptake), and model structures (e.g., using different soil constitutive and/or hydrological models). Considering all these sources of uncertainties, however, will compromise the efficiency (i.e., computational time) of the evolutionary process. Under this setup, the analysis of uncertainties should be done with care because they are not of Bayesian type.

[19] A cross validation of the soil hydraulic parameters derived from methods 1 and 2 was performed to check if the parameters derived from one modeling condition (i.e., initial/bottom boundary ensembles) are applicable to the other modeling conditions used.

\subsection{Data and Experiments}

\subsubsection{Locations of the Study}

[20] Figure 2 shows the locations of the selected fields in the Southern Great Plains 1997 (SGP97) Hydrology Experiment and the Soil Moisture Experiment 2002 (SMEX02) regions used in this study. We selected these fields or airborne RS footprints because of the availability of ground-truth soil moisture and soil hydraulic properties data sets collected using spatially distributed sampling schemes during the field campaigns for in situ and laboratory measurements [Mohanty and Skaggs, 2001; Jacobs et al., 2004; Mohanty et al., 2002] (see also B. P. Mohanty, unpublished data, 2006, http://vadosezone.tamu.edu). These data sets can be used to validate the RS footprint-scale results based on the IM-based near-surface soil moisture assimilation experiments.

Table 2a. Derived Effective Soil Hydraulic Parameters for SGP97 Fields LW03, LW13, and LW21 Using Method 1 Under Groundwater Conditions

\begin{tabular}{lcccccc}
\hline & Statistics & $\begin{array}{c}\alpha \\
\left(\mathrm{cm}^{-1}\right)\end{array}$ & $\begin{array}{c}n \\
()\end{array}$ & $\begin{array}{c}\theta_{\text {res }} \\
\left(\mathrm{cm}^{3} \mathrm{~cm}^{-3}\right)\end{array}$ & $\begin{array}{c}\theta_{\text {sat }} \\
\left(\mathrm{cm}^{3} \mathrm{~cm}^{-3}\right)\end{array}$ & $\begin{array}{c}K_{\text {sat }} \\
\left(\mathrm{cm} \mathrm{d}^{-1}\right)\end{array}$ \\
\hline LW03 & Mean & 0.022 & 1.601 & 0.101 & 0.373 & 46.0 \\
& SD & 0.006 & 0.012 & 0.005 & 0.005 & 6.1 \\
LW13 & Mean & 0.023 & 1.570 & 0.062 & 0.391 & 30.3 \\
& SD & 0.006 & 0.043 & 0.001 & 0.020 & 15.3 \\
LW21 & Mean & 0.026 & 1.577 & 0.118 & 0.379 & 30.7 \\
& SD & 0.006 & 0.027 & 0.008 & 0.010 & 14.9 \\
\hline
\end{tabular}


Table 2b. Derived Effective Soil Hydraulic Parameters for SGP97 Fields LW03, LW13, and LW21 Using Method 1 Under FreeDrainage Conditions

\begin{tabular}{lcccccc}
\hline & Statistics & $\begin{array}{c}\alpha \\
\left(\mathrm{cm}^{-1}\right)\end{array}$ & $\begin{array}{c}n \\
()\end{array}$ & $\begin{array}{c}\theta_{\text {res }} \\
\left(\mathrm{cm}^{3} \mathrm{~cm}^{-3}\right)\end{array}$ & $\begin{array}{c}\theta_{\text {sat }} \\
\left(\mathrm{cm}^{3} \mathrm{~cm}^{-3}\right)\end{array}$ & $\begin{array}{c}K_{\text {sat }} \\
\left(\mathrm{cm} \mathrm{d}^{-1}\right)\end{array}$ \\
\hline LW03 & Mean & 0.006 & 1.479 & 0.068 & 0.41 & 53.9 \\
& SD & 0.001 & 0.053 & 0.014 & 0.02 & 1.4 \\
LW13 & Mean & 0.007 & 1.595 & 0.063 & 0.538 & 36.221 \\
& SD & 0.001 & 0.015 & 0.003 & 0.013 & 10.544 \\
LW21 & Mean & 0.009 & 1.417 & 0.126 & 0.388 & 41.4 \\
& SD & 0.008 & 0.098 & 0.010 & 0.023 & 12.7 \\
\hline
\end{tabular}

[21] The selected fields/RS footprints from SGP97 sites in Oklahoma are composed of LW03, LW13, and LW21 of Little Washita (LW) watershed (Figure 2a). The LW03 field is characterized by a mixture of sandy loam and loam with grass cover, while the LW13 field is characterized by a mixture of silt loam and loam with grass cover. The LW21 field, on the other hand, is characterized by a mixture of silt loam and loam with grass/wheat vegetation cover. Daily weather data for the period of January-December 1997 were collected from different U.S. Department of Agriculture Agricultural Research Service (USDA-ARS) micronet sites, nearest to the selected fields. Here we used micronet sites ARS124, ARS136, and ARS151 for LW03, LW13, and LW21, respectively (http://grl.ars.usda.gov/micronet/). More detailed descriptions of the selected SGP97 study sites and ground soil moisture sampling protocols are given by Mohanty and Skaggs [2001].

[22] The selected SMEX02 fields in Iowa are WC11, WC12, WC13, and WC14 of the Walnut Creek (WC) watershed (Figure 2b). The WC11 field consists of a mixture of clay loam and loam, and a cropped area with primarily corn and a patch of soybean. The WC12 field is also characterized by a mixture of clay loam and loam and planted to corn. The WC13 and WC14 fields have a mixture of clay loam, loam and silty clay loam, and planted to rowcropped (WC13) and broadcasted (WC14) soybean. Daily weather data from January-December 2002 were collected from a nearby Soil-Climate-Analysis-Network (SCAN) station at Ames, Iowa [Jackson, 2002] (see also http:// www.wcc.nrcs.usda.gov/scan/). We used only one set of daily weather data for these four adjacent fields/RS footprints WC11, WC12, WC13, and WC14 in the model simulation and inverse analyses. Detailed descriptions of the selected SMEX02 field sites and ground soil moisture sampling protocols can also be found elsewhere [Jacobs et al., 2004].

\subsubsection{Airborne RS Near-Surface Soil Moisture Data}

[23] In Oklahoma, airborne L-band passive microwave remote sensor electronically scanned thinned array radiometer (ESTAR) soil moisture data sets [Jackson et al., 1999] from the SGP97 campaign database (http://disc.gsfc.nasa. gov/fieldexp/SGP97/estar.html), ranging from DOY 169171, 176-178, 180-184, 192-195, and 197 (June-July 1997), were processed with ENVI image processing software [Research Systems, Inc., 2003]. The 16 ESTAR soil moisture data were georeferenced and stacked as a series of map layers in an ascending order, based on the day of year (DOY) for easy retrieval of the time series of soil moisture data. The ESTAR footprints/pixels corresponding to the locations of LW03, LW13, and LW21 (Figure 2a) were determined and the time series of near-surface soil moisture data were extracted (Figure 3a) for the inverse analyses.

[24] In Iowa, airborne C-band passive microwave remote sensor Polarimetric Scanning Radiometer (PSR) soil moisture data [Bindlish, 2004] from the SMEX02 campaign (http://nsidc.org/data/amsr_validation/soil_moisture/smex02/) were used for the inverse analyses. The data contained near-surface soil moisture measurements of DOY 176, 178, 180, 182, 185, 189, and 190-193 (June-July 2002). The 10 PSR soil moisture images were georeferenced and

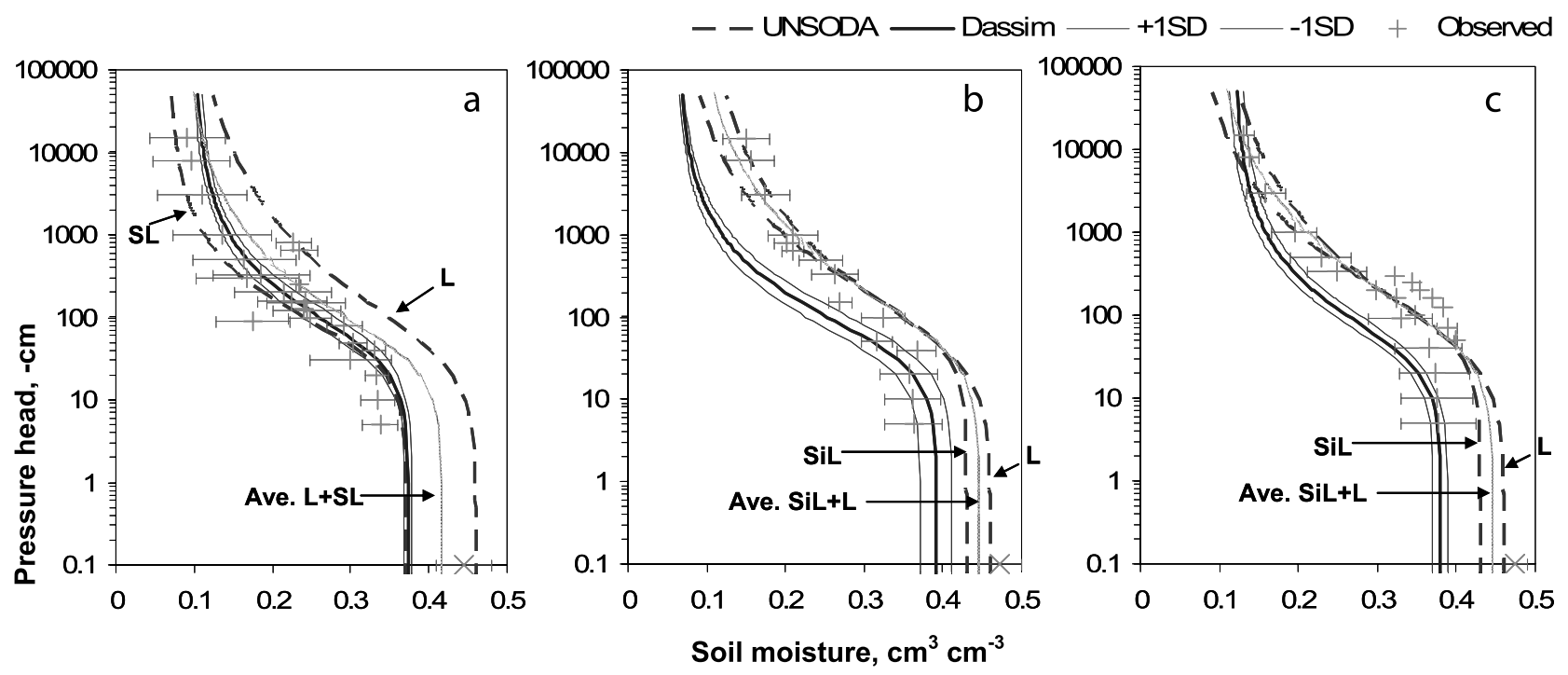

Figure 4. Comparison of derived $\theta(h)$ (Dassim) from method 1 under groundwater conditions, UNSODA and observed (field average and spread) soil water retention curves for the selected fields at SGP97 site: (a) LW03 ( $\mathrm{N}=20)$, (b) LW13 ( $\mathrm{N}=17)$, and (c) LW21 $(\mathrm{N}=5)$. $\mathrm{N}$ indicates the number of samples; $\mathrm{L}$ is $1 \quad \mathrm{~L}$ is sandy loam, and SiL is silt loam. 
-- UNSODA — Dassim _ +
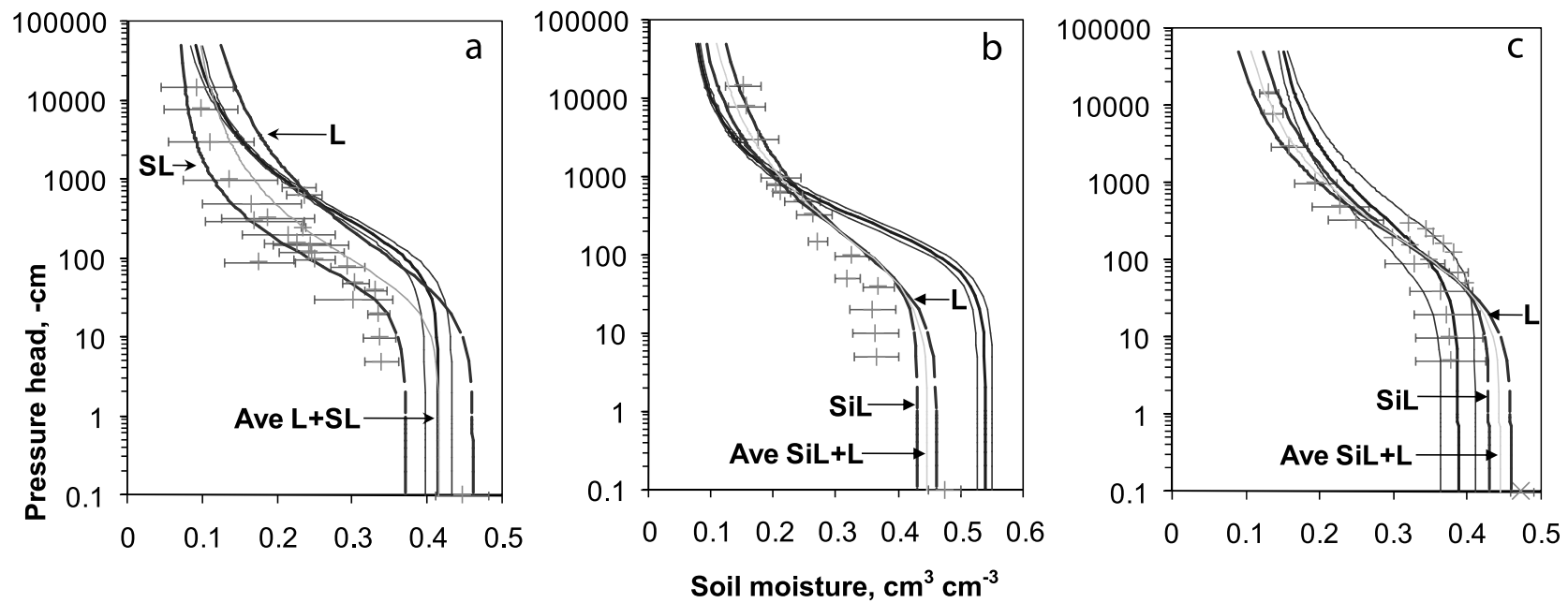

Figure 5. Comparison of derived $\theta(h)$ (Dassim) from method 1 under free drainage conditions, UNSODA and observed (field average and spread) soil water retention curves for the selected fields at SGP97 site: (a) LW03 ( $\mathrm{N}=20)$, (b) LW13 ( $\mathrm{N}=17)$, and (c) LW21 ( $\mathrm{N}=5)$. N indicates the number of samples; L is loam, SL is sandy loam, and SiL is silt loam.

stacked in the same manner as that of the ESTAR data. Furthermore, we located the PSR footprints/pixels colocated with the geographic locations of the WC11, WC12, WC13, and WC14 fields (Figure 2b), and then we extracted the time series of soil moisture data for the inverse analyses (Figure 3b). Both PSR (SMEX02) and ESTAR (SGP97) based remotely sensed soil moisture data have $800 \mathrm{~m} \times 800 \mathrm{~m}$ footprint/pixel resolutions. Both PSR and ESTAR have soil moisture observation depths of $5 \mathrm{~cm}$. Uncertainties associated with the data could mainly come from the data processing and retrieval algorithm of soil moisture from passive microwave based brightness temperature, and associated within-pixel variability of soil texture, topography, vegetation, and systemic errors from the airborne sensors/aircraft operations.

\subsubsection{Soil Hydraulic Properties Measurement}

[25] For the SGP97 region, we collected soil cores from different depths at representative (soil, topography, and vegetation) sites based on a priori information from digital maps (http://www.essc.psu.edu/nasa_lsh/) and site inspection. Although in the database we provided more detailed and unbounded site classifications for future researchers, various combinations of soil texture (12 USDA classes), relative position (valley, hillslope, hilltop), and vegetation type (grass, shrub, crop) were used as the primary groups for our site selection protocol. A total of 157 surface soil cores were collected from 46 quarter sections within the Little Washita (LW), El Reno (ER), and Central Facility (CF) intensive study areas. In addition to the surface cores, four or five subsurface soil cores were collected at depths of up to $1 \mathrm{~m}$ at selected sites (based on soil morphologic characteristics) within the LW, ER, and CF areas. Soil cores were analyzed in the laboratory for soil hydraulic properties [Mohanty et al., 2002]. Similar soil core sampling protocols were followed for the SMEX02 region. A total of 50 sets of soil water retention and hydraulic conductivity observations were made within the Walnut Creek watershed in Iowa
(B. P. Mohanty, unpublished data, 2006, http://vadosezone. tamu.edu).

\subsubsection{Numerical Experiments}

[26] Considering a typical dynamic vadose zone of $2 \mathrm{~m}$ depth (from the soil surface), we conducted the numerical experiments for parameter estimation with the notion that our soil hydrologic modeling domains are effective in nature (i.e., reflecting the resultant behavior of hydrologic processes in the spatially heterogeneous porous medium). Hence we used pixel-representative (i.e., $800 \mathrm{~m} \times 800 \mathrm{~m}$ ) hydroclimatic forcings and validation data in the simulations, such as representative crop/vegetation, precipitation, and other meteorological variables and remotely sensed/ regional in situ soil moisture data [Mohanty et al., 2002, 2000; Mohanty and Skaggs, 2001; Jacobs et al., 2004]. The effective soil hydraulic properties that characterize the modeling domain were determined by the GA-based inverse modeling using the available time series of RS near-surface soil moisture data as conditioning criteria. A wide range of soils (from clay loam to sandy loam in terms of soil hydraulic parameter values) were used as search spaces during the inverse analyses matching the concept of effective parameters rather than any dominant soil texture within the study pixel (see Table 1).

[27] For methods 1 and 2 (section 2.1) we considered two major bottom/lower boundary conditions. First, a lower boundary condition prescribed by a groundwater table and, second, a lower boundary prescribed under a freedrainage condition (i.e., $\partial h / \partial z=0$ ). Under the groundwater condition, we used three modeling conditions (ensembles), namely, 100-, 150-, and 200-cm water table depths. For the free-drainage condition, three modeling conditions (ensembles) were considered as well, uniform soil profile initial conditions of $-100-,-500-$, and $-1000-\mathrm{cm}$ pressure heads, respectively. Under water table conditions the initial profile soil water pressures are in equilibrium with the groundwater table. In summary, the number of modeling conditions used 

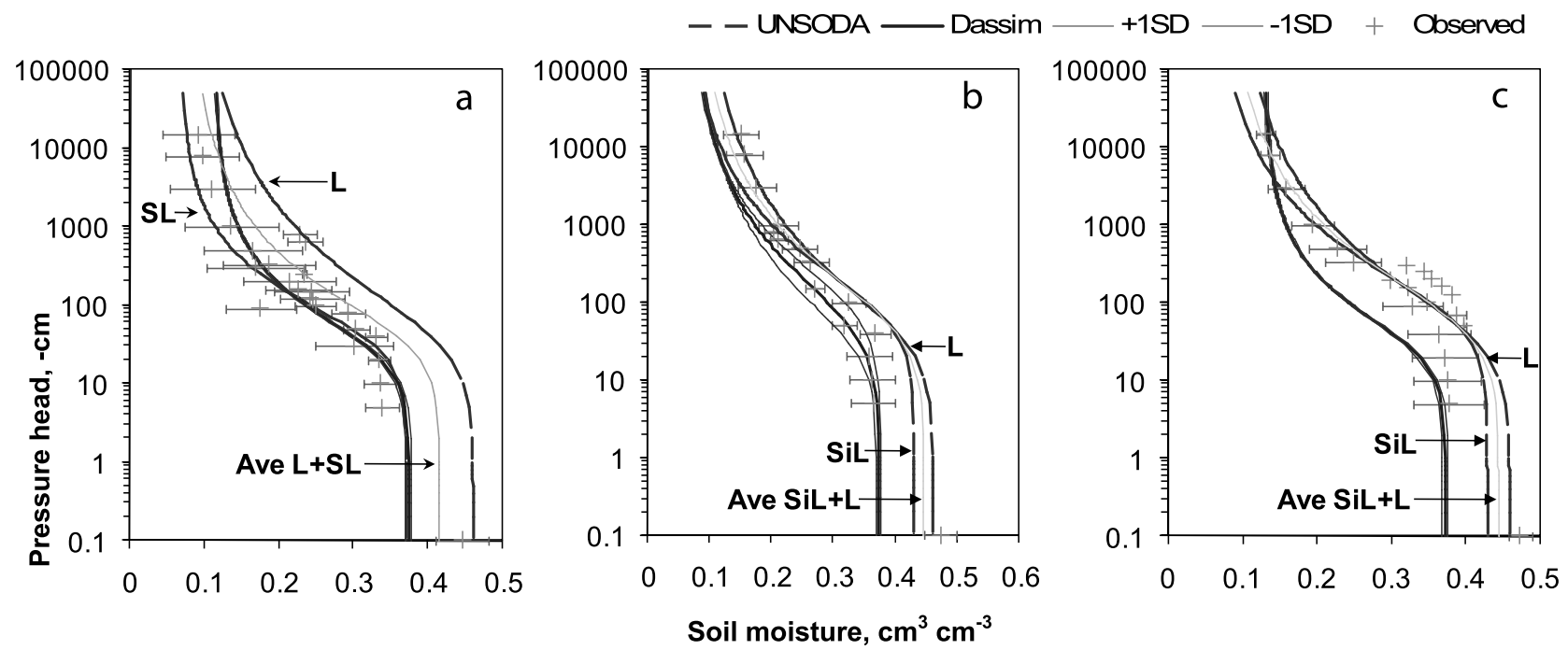

Figure 6. Comparison of derived $\theta(h)$ (Dassim) from method 2 (i.e., under all groundwater and free drainage conditions, collectively), UNSODA and observed (field average and spread) soil water retention curves for the selected fields at SGP97 site: (a) LW03 ( $\mathrm{N}=20)$, (b) LW13 (N=17), and (c) LW21 (N=5). $\mathrm{N}$ indicates the number of samples; $\mathrm{L}$ is loam, SL is sandy loam, and SiL is silt loam.

for method 1 are three for groundwater, and three for freedrainage conditions, respectively (equation (3)), and in method 2 there are six different modeling conditions used (all groundwater and free-drainage conditions simultaneously; equations (5) and (7)).

[28] In SGP97 pixels, the simulation periods for fields LW03 and LW13 included 1 January to 31 December 1997 , where SWAP models grass cover as an annual crop with a 365-d cycle. Nevertheless, we only considered the simulated near-surface soil moisture data $\theta(\mathrm{z}=0-5 \mathrm{~cm}, t)$ corresponding to the DOYs when RS soil moisture data were available for evaluating the fitness of a generated combination of parameters $\mathbf{p}$ '. We used wheat crop as the dominant vegetation cover for the LW21 field. Note, however, that during the SGP97 campaign the wheat crops were already harvested. To include the wheat cropping season in the simulations and allow enough time for model spinning/initialization prior to the growing season, the SWAP model was run during 1 September 1996 to 31 August 1997.

[29] For SMEX02 pixels, we considered corn as the dominant vegetation cover for the WC11 and $\mathrm{WC} 12$ fields, and the simulations covered the period from 1 May to 31 October 2002. Similarly, the simulation periods for fields WC13 and WC14 with predominantly soybean cover also included from 1 May to 31 October 2002. All these gently rolling fields/footprints in the SMEX02 and SGP97 regions were considered flat from the runoff and run-on generation perspective, and thus the resultant water flow was only in vertical direction at the model domain/airborne RS footprint scale $(800 \mathrm{~m} \times 800 \mathrm{~m})$. SWAP uses the rootwater uptake model of Feddes et al. [1978] to model the root-soil moisture dynamics in the vadose zone. Here we used measured rooting depths as inputs to the root-water uptake model. A trapezoidal root density was assumed for all the simulations in SMEX02 and SGP97 sites.

[30] For the multidata analysis (equation (7)), we used airborne RS and regional u soil moisture data [Mohanty and Skaggs, 2001; Jacobs et al., 2004] as our sources of replicates. All inverse modeling runs performed in this study were applied within the multipopulated GA framework outlined by Ines and Mohanty [2008a].

\subsection{Cross Validation of Derived Effective $\boldsymbol{\theta}(h), K(h)$,} and $\theta(z, t)$

[31] From the inverse modeling based on methods 1 and 2 described earlier, we compared the derived $\theta(h)$ and $K(h)$ with the (arithmetic) average soil hydraulic functions (1)

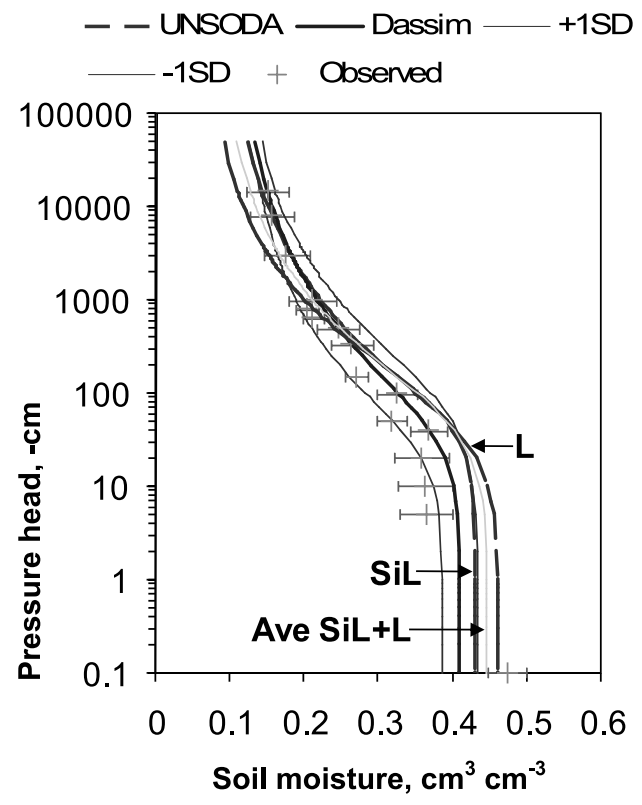

Figure 7. Comparison of derived $\theta(h)$ (Dassim) from method 2 under multidata analysis, UNSODA and observed (field average and spread) soil water retention curves for the LW13 $(\mathrm{N}=17)$ field at SGP97 site. $\mathrm{N}$ indicates the number of samples; L is loam, SL is sandy loam, and SiL is silt loam. 

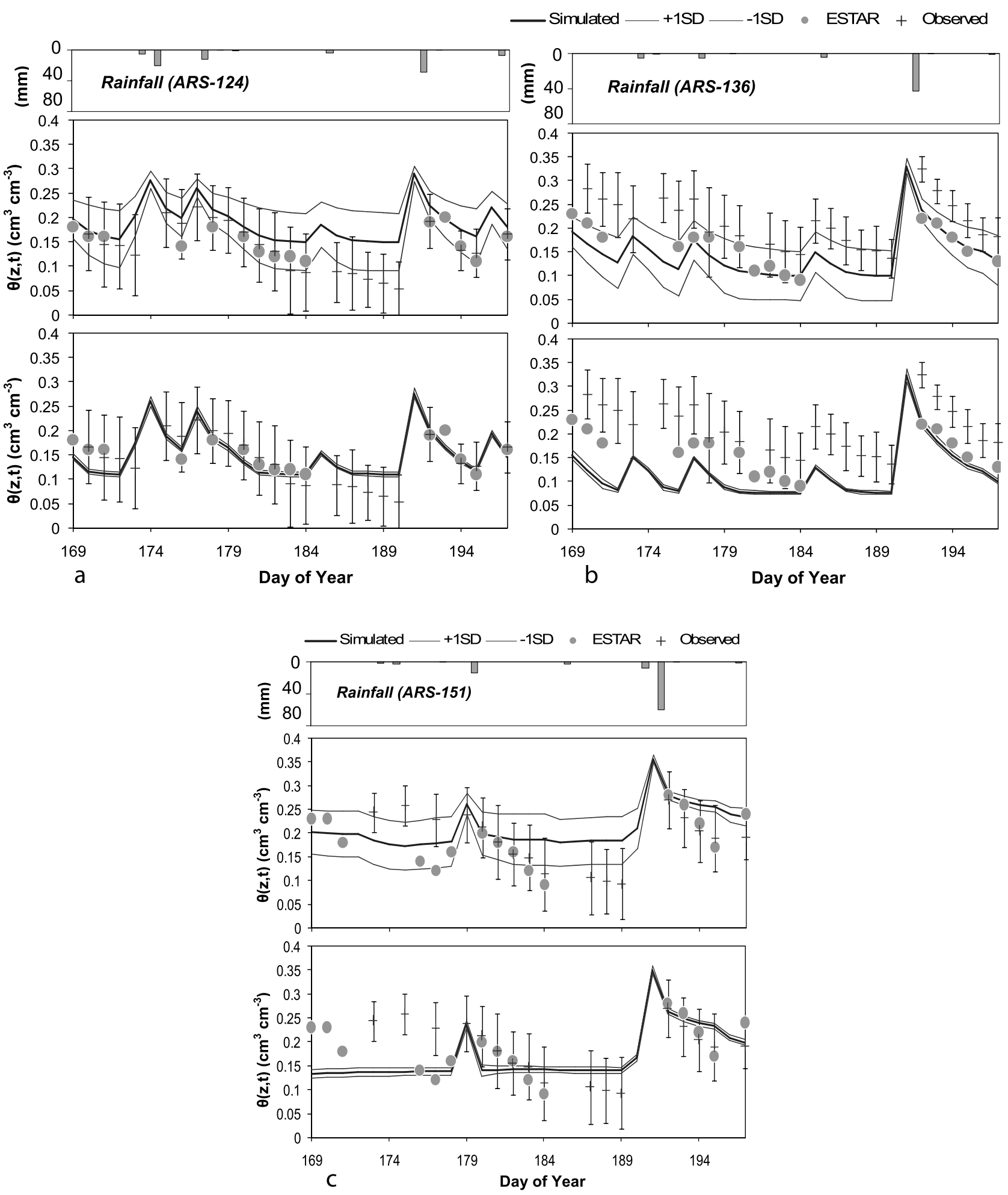

Figure 8. Simulated and cross-validated near-surface soil moisture $(z=0-5 \mathrm{~cm})$ using method 1 under groundwater conditions versus ESTAR and observed areal-average (with spread) soil moisture during SGP97: (a) LW03 ( $\mathrm{N}=49)$, (b) LW13 $(\mathrm{N}=49)$, and (c) LW21 ( $=49)$. $\mathrm{N}$ indicates the number of samples. Top panels are applied to all groundwater conditions; bottom panels are applied to all free drainage conditions.

measured using the soil cores collected from the fields [Mohanty et al., 2002] and (2) for the dominant soil textures at the particular fields/RS footprints from the UNSODA database [Leij et al., 1999
[32] We cross validated the estimated $\theta(h)$ and $K(h)$ by comparing the simulated near-surface soil moisture and the areal-average near-surface soil moisture measured by ground-based theta probes across the LW03, LW13, and 

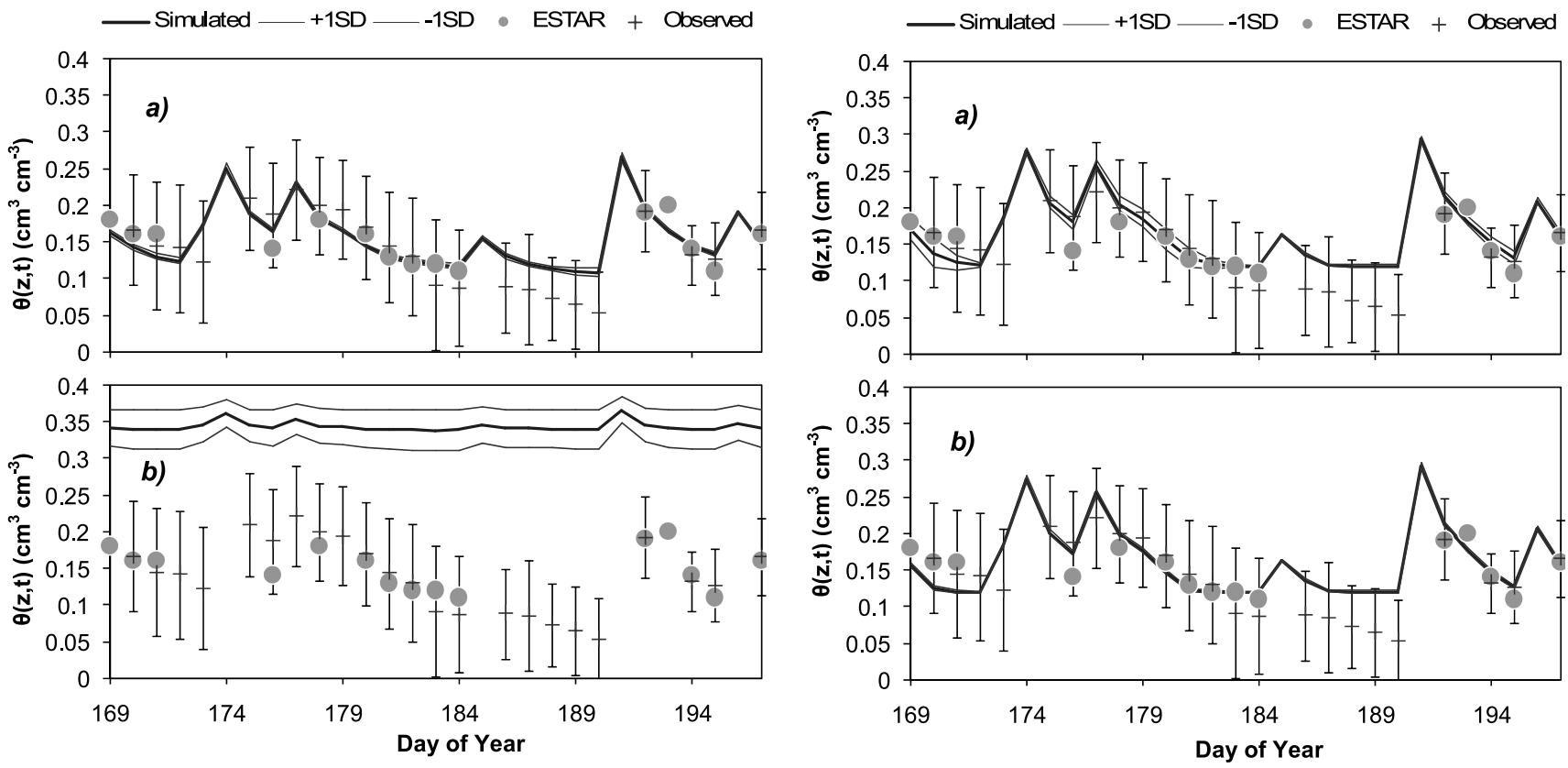

Figure 9. Sample results of simulated and cross-validated near-surface soil moisture $(z=0-5 \mathrm{~cm})$ using method 1 under free drainage conditions versus ESTAR and observed areal-average (with spread) soil moisture at LW03 $(\mathrm{N}=49)$ during SGP97: (a) applied to all free drainage conditions and (b) applied to all groundwater conditions. $\mathrm{N}$ indicates the number of samples.

LW21 (SGP97) fields [Mohanty and Skaggs, 2001] and the WC11, WC12, WC13, and WC14 (SMEX02) fields [Jacobs et al., 2004]. The cross validation was performed by applying the derived soil hydraulic functions across the ensemble of modeling conditions (i.e., $\theta(h)$ and $K(h)$ derived from groundwater boundary conditions were applied to both groundwater and free-drainage conditions, and vice versa). Mean, standard deviation, correlation coefficient (R), mean bias error (MBE), and root mean square error (RMSE) of modeled and measured values were used to evaluate the performance of the GA-based inverse modeling and near-surface soil moisture assimilation in deriving the effective soil hydraulic properties at the footprint of the airborne sensors.

[33] The average areal soil water retention and hydraulic conductivity functions are derived using equations (9) and $(10)$, and the areal near-surface soil moisture was determined using equation (11), where $\bar{\theta}(h)$ is the average soil water retention at pressure head $h ; \theta_{i}(h)$ is the soil water

Table 2c. Derived Effective Soil Hydraulic Parameters for SGP97 Fields LW03, LW13, and LW21 Using Method 2 (Under All Groundwater and Free-Drainage Conditions, Collectively)

\begin{tabular}{lcccccc}
\hline & Statistics & $\begin{array}{c}\alpha \\
\left(\mathrm{cm}^{-1}\right)\end{array}$ & $\begin{array}{c}n \\
()\end{array}$ & $\begin{array}{c}\theta_{\text {res }} \\
\left(\mathrm{cm}^{3} \mathrm{~cm}^{-3}\right)\end{array}$ & $\begin{array}{c}\theta_{\text {sat }} \\
\left(\mathrm{cm}^{3} \mathrm{~cm}^{-3}\right)\end{array}$ & $\begin{array}{c}K_{\text {sat }} \\
\left(\mathrm{cm} \mathrm{d}^{-1}\right)\end{array}$ \\
\hline LW03 & Mean & 0.032 & 1.601 & 0.113 & 0.374 & 44.735 \\
& SD & 0.001 & 0.010 & 0.002 & 0.004 & 4.616 \\
LW13 & Mean & 0.021 & 1.370 & 0.065 & 0.373 & 27.157 \\
& SD & 0.010 & 0.048 & 0.004 & 0.004 & 14.684 \\
LW21 & Mean & 0.032 & 1.602 & 0.129 & 0.373 & 12.409 \\
& SD & 0.001 & 0.005 & 0.002 & 0.004 & 1.097
\end{tabular}

Figure 10. Sample results of simulated and crossvalidated near-surface soil moisture $(z=0-5 \mathrm{~cm})$ using method 2 (i.e., under all groundwater and free drainage conditions, collectively) versus ESTAR and observed arealaverage (with spread) soil moisture at LW03 $(\mathrm{N}=49)$ during SGP97: (a) applied to all groundwater conditions and (b) applied to all free drainage conditions. $\mathrm{N}$ indicates the number of samples.

retention for soil sample $i$ at pressure head $h ; \bar{K}(h)$ is the average unsatured/saturated hydraulic conductivity at pressure head $h ; K_{i}(h)$ is the unsaturated/saturated hydraulic conductivity of soil core sample $i$ at pressure head $h ; N$ is the number of soil core samples for hydraulic property measurements or soil moisture sampling points; and $\bar{\theta}(z, t)$ is the areal-average near-surface $(z=0-5 \mathrm{~cm})$ soil moisture on day $t$.

$$
\begin{gathered}
\bar{\theta}(h)=\frac{1}{N} \sum_{i=1}^{N} \theta_{i}(h) \quad \forall h \\
\bar{K}(h)=\frac{1}{N} \sum_{i=1}^{N} K_{i}(h) \quad \forall h
\end{gathered}
$$

Table 2d. Derived Effective Soil Hydraulic Parameters Using

\begin{tabular}{|c|c|c|c|c|c|c|}
\hline & Statistics & $\begin{array}{c}\alpha \\
\left(\mathrm{cm}^{-1}\right)\end{array}$ & $\begin{array}{l}n \\
()\end{array}$ & $\begin{array}{c}\left.\begin{array}{c}\theta_{\text {res }} \\
\left(\mathrm{cm}^{3} \mathrm{~cm}^{-3}\right)\end{array}\right)\end{array}$ & $\begin{array}{c}\theta_{\text {sat }} \\
\left(\mathrm{cm}^{3} \mathrm{~cm}^{-3}\right)\end{array}$ & $\begin{array}{c}K_{\text {sat }} \\
\left(\mathrm{cm} \mathrm{d}^{-1}\right)\end{array}$ \\
\hline \multicolumn{7}{|c|}{ SGP97 } \\
\hline \multirow[t]{2}{*}{ LW13 } & Mean & 0.022 & 1.351 & 0.096 & 0.409 & 13.312 \\
\hline & $\mathrm{SD}$ & 0.009 & 0.102 & 0.029 & 0.023 & 9.705 \\
\hline \multicolumn{7}{|c|}{ SMEX02 } \\
\hline \multirow[t]{2}{*}{ WC12 } & Mean & 0.031 & 1.581 & 0.128 & 0.376 & 53.148 \\
\hline & SD & 0.005 & 0.038 & 0.023 & 0.008 & 4.970 \\
\hline
\end{tabular}
Method 2 Under Multidata Analysis 


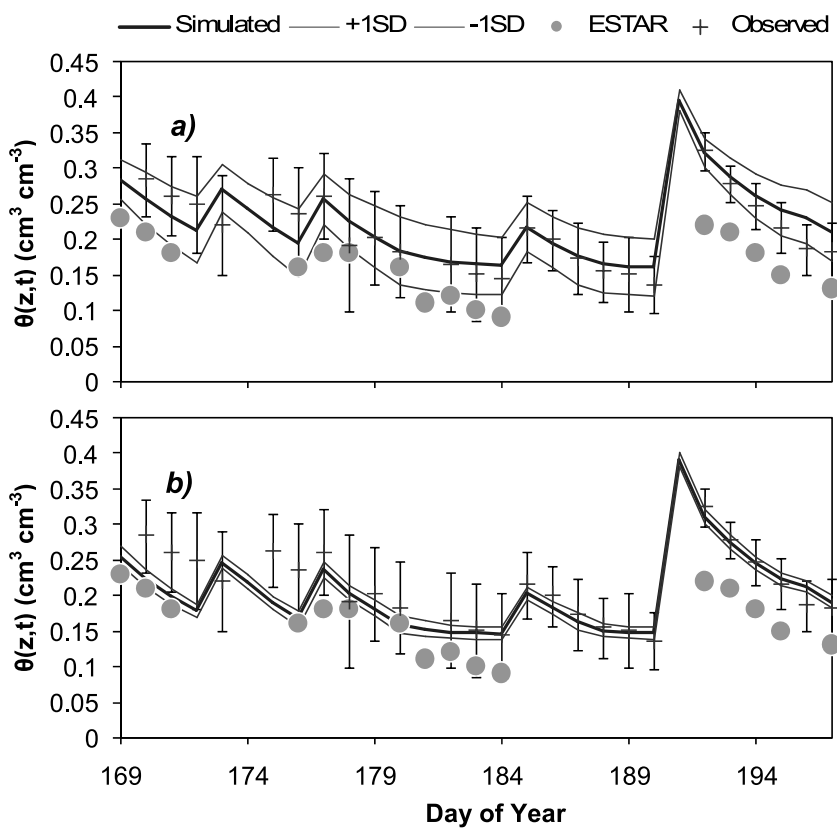

Figure 11. Sample results of simulated and cross-validated near-surface soil moisture $(z=0-5 \mathrm{~cm})$ using method 2 under multidata analysis versus ESTAR and observed areal-average (with spread) soil moisture at LW13 ( $\mathrm{N}=49)$ during SGP97: (a) applied to all groundwater conditions and (b) applied to all free drainage conditions. $\mathrm{N}$ indicates the number of samples.

$$
\bar{\theta}(z, t)=\frac{1}{N} \sum_{i=1}^{N} \theta_{i}(z, t) \quad \forall t .
$$

\section{Results and Discussions}

\subsection{SGP97 Sites, Oklahoma}

3.1.1. Effective Soil Hydraulic Properties and Soil Moisture for Selected SGP97 Fields

[34] Tables $2 \mathrm{a}$ and $2 \mathrm{~b}$ show the derived effective soil hydraulic parameters for each selected SGP97 fields (LW03,

Table 3a. Performance of Method 1 Under Groundwater Conditions at SGP97 Sites ${ }^{\mathrm{a}}$

\begin{tabular}{|c|c|c|c|c|c|c|}
\hline \multirow[b]{2}{*}{ Fields } & \multicolumn{3}{|c|}{ Simulated Versus RS } & \multicolumn{3}{|c|}{ Simulated Versus Ground } \\
\hline & $\mathrm{R}$ & MBE & RMSE & $\mathrm{R}$ & MBE & RMSE \\
\hline \multicolumn{7}{|c|}{ Applied to All Groundwater Conditions } \\
\hline LW03 & 0.81 & 0.035 & 0.046 & 0.84 & 0.040 & 0.032 \\
\hline LW13 & 0.86 & -0.016 & 0.027 & 0.81 & -0.073 & 0.080 \\
\hline LW21 & 0.73 & 0.025 & 0.044 & 0.47 & 0.026 & 0.044 \\
\hline \multicolumn{7}{|c|}{ Applied to All Free Drainage Conditions } \\
\hline LW03 & 0.74 & -0.005 & 0.036 & 0.76 & 0.000 & 0.026 \\
\hline LW13 & 0.78 & -0.045 & 0.053 & 0.71 & -0.102 & 0.110 \\
\hline LW21 & 0.61 & -0.017 & 0.048 & 0.48 & -0.012 & 0.042 \\
\hline
\end{tabular}

Table 3b. Performance of Method 1 Under Free Drainage Conditions at SGP97 Sites

\begin{tabular}{|c|c|c|c|c|c|c|}
\hline \multirow[b]{2}{*}{ Fields } & \multicolumn{3}{|c|}{ Simulated Versus RS } & \multicolumn{3}{|c|}{ Simulated Versus Ground } \\
\hline & $\mathrm{R}$ & MBE & RMSE & $\mathrm{R}$ & MBE & RMSE \\
\hline \multicolumn{7}{|c|}{ Applied to All Groundwater Conditions } \\
\hline LW03 & 0.65 & 0.193 & 0.195 & 0.58 & 0.203 & 0.195 \\
\hline LW13 & 0.79 & 0.241 & 0.244 & 0.76 & 0.192 & 0.187 \\
\hline LW21 & 0.66 & 0.005 & 0.040 & 0.51 & 0.008 & 0.040 \\
\hline \multicolumn{7}{|c|}{ Applied to All Free Drainage Conditions } \\
\hline LW03 & 0.81 & 0.003 & 0.030 & 0.85 & 0.006 & 0.019 \\
\hline LW13 & 0.86 & -0.018 & 0.030 & 0.82 & -0.075 & 0.082 \\
\hline LW21 & 0.65 & 0.109 & 0.118 & 0.51 & 0.110 & 0.112 \\
\hline
\end{tabular}

LW13, LW21) under groundwater and free-drainage conditions using method 1 (see section 2.1). In method 1, the soil hydraulic parameters are determined under different modeling conditions independently (under the multipopulation framework). Then the solutions from these individual conditions are aggregated to form the final solution of the inverse problem. In this part of the study, we made distinctions between groundwater and free-drainage conditions as lower boundary conditions to validate if those parameters derived under one condition are applicable or not to other modeling conditions. Apparently, the derived effective soil hydraulic parameters from groundwater conditions are not similar to those derived from free-drainage conditions (Tables $2 \mathrm{a}$ and $2 \mathrm{~b}$ ). It appears that the soil hydraulic parameters derived from free-drainage conditions depict wetter soil hydraulic functions, i.e., higher saturated soil moisture contents and higher bubbling pressures (i.e., lesser $\alpha$ values) (see Figures 4 and 5; see also Figures 6 and 7). Interesting characteristics of these functions are more evident after we applied them in forward modeling.

[35] In Figures $8 \mathrm{a}-8 \mathrm{c}$, the responses of our SGP97 modeling domains (LW03, LW13, LW21) from forward modeling are shown. These soil moisture dynamics were simulated using soil hydraulic parameters derived from method 1 under groundwater conditions (Table 2a). It is evident that the parameters used are applicable for both groundwater (Figures $8 \mathrm{a}-8 \mathrm{c}$, top plots) and free drainage conditions (Figures $8 \mathrm{a}-8 \mathrm{c}$, bottom plots), suggesting the robustness of the derived soil hydraulic parameters. The apparent variability of the simulated soil moisture contents

Table 3c. Performance of Method 2 (Under All Groundwater and Free Drainage Conditions, Collectively) at SGP97 Sites

\begin{tabular}{|c|c|c|c|c|c|c|}
\hline \multirow[b]{2}{*}{ Fields } & \multicolumn{3}{|c|}{ Simulated Versus RS } & \multicolumn{3}{|c|}{ Simulated Versus Ground } \\
\hline & $\mathrm{R}$ & MBE & RMSE & $\mathrm{R}$ & MBE & RMSE \\
\hline \multicolumn{7}{|c|}{ Applied to All Groundwater Conditions } \\
\hline LW03 & 0.78 & 0.011 & 0.038 & 0.81 & 0.015 & 0.019 \\
\hline LW13 & 0.90 & -0.001 & 0.020 & 0.87 & -0.059 & 0.065 \\
\hline LW21 & 0.72 & 0.006 & 0.037 & 0.49 & 0.007 & 0.041 \\
\hline \multicolumn{7}{|c|}{ Applied to All Free Drainage Conditions } \\
\hline LW03 & 0.75 & 0.006 & 0.037 & 0.77 & 0.011 & 0.022 \\
\hline LW13 & 0.81 & -0.015 & 0.031 & 0.76 & -0.071 & 0.081 \\
\hline LW21 & 0.65 & 0.001 & 0.041 & 0.52 & 0.005 & 0.039 \\
\hline
\end{tabular}


Table 3d. Performance of Method 2 Under Multidata Analysis

\begin{tabular}{lcccccccc}
\hline & \multicolumn{3}{c}{ Simulated Versus RS } & & \multicolumn{5}{c}{ Simulated Versus Ground } \\
\cline { 2 - 3 } Fields & $\mathrm{R}$ & MBE & RMSE & & $\mathrm{R}$ & MBE & RMSE & Remarks \\
\hline LW13 & 0.90 & 0.064 & 0.067 & 0.87 & 0.004 & 0.022 & SGP97 \\
WC12 & 0.76 & 0.022 & 0.049 & 0.92 & 0.102 & 0.106 & SMEX02 \\
& \multicolumn{7}{c}{ Applied to All Free Drainage Conditions } & \\
LW13 & 0.86 & 0.042 & 0.049 & & 0.81 & -0.016 & 0.032 & SGP97 \\
WC12 & 0.79 & 0.010 & 0.046 & 0.90 & 0.088 & 0.093 & SMEX02 \\
\hline
\end{tabular}

under groundwater conditions can be attributed to the variable responses of the modeling domains using parameters derived from one groundwater condition (see section 2.2.4) and then applying them to the others in the forward modeling, and vice versa. It also suggests that soil hydraulic parameters derived from one groundwater condition are not exactly the same from the parameters derived from the other modeled groundwater conditions (see section 2.2.4). Further analysis showed that parameters derived under a deeper water table scenario have produced wetter near-surface soil moisture contents when being applied at a shallower water table condition (not shown).

[36] Figures 9a and 9b also shows a sample forward modeling results (LW03 field) using soil hydraulic parameters derived by method 1 under free drainage conditions (Table 2b). Apparently, the parameters performed well under free drainage conditions (Figure 9a) with small variability in the simulated near-surface soil moisture. However, when applied under groundwater conditions (Figure 9b), it is evident that the simulated soil moisture contents are too wet compared with the observed RS and in situ soil moisture data. This was expected because of the wetter soil hydraulic functions derived by method 1 under free drainage conditions (Table 2b; Figure 5). This behavior is consistent with the other SGP97 fields.

[37] The preceding discussion suggests that the parameters derived by method 1 are mostly applicable to the modeling conditions they were subject from, with a small exception for parameters derived under groundwater conditions. The question remains then, How can we derive a set of soil hydraulic parameters that are effective for all modeling conditions? Method 2 was designed to address this question in which the parameter search was evaluated against all modeling conditions (groundwater and free drainage) simultaneously (see section 2.1). Since we are looking for sets of soil hydraulic parameters that are effective for all modeling conditions, it is hypothesized that these parameter sets are narrow in variability so that they can satisfy all the modeling conditions used for replicating the near-surface RS soil moisture. Table 2c shows the effective soil hydraulic parameters derived for LW03, LW13, and LW21 fields using method 2. At a glance, they seem to correspond well with those parameters derived under groundwater conditions in method 1, but Figure 6 shows that they are different. Aside from the narrower variability of the derived soil hydraulic functions, some significant improvements are observed especially for the case of LW13 field (Figure 6b versus Figures $4 b$ and $5 b$ ). This result suggests that there could be variability in
Table 4a. Derived Effective Soil Hydraulic Parameters for SMEX02 Fields WC11, WC12, WC13, and WC14 Using Method 1 Under Groundwater Conditions

\begin{tabular}{ccccccc}
\hline & Statistics & $\begin{array}{l}\alpha \\
\left(\mathrm{cm}^{-1}\right)\end{array}$ & $\begin{array}{c}n \\
()\end{array}$ & $\begin{array}{c}\theta_{\text {res }} \\
\left(\mathrm{cm}^{3} \mathrm{~cm}^{-3}\right)\end{array}$ & $\begin{array}{c}\theta_{\text {sat }} \\
\left(\mathrm{cm}^{3} \mathrm{~cm}^{-3}\right)\end{array}$ & $\begin{array}{c}K_{\text {sat }} \\
\left(\mathrm{cm} \mathrm{d}^{-1}\right)\end{array}$ \\
\hline WC11 & Mean & 0.024 & 1.599 & 0.137 & 0.373 & 33.3 \\
& SD & 0.005 & 0.010 & 0.005 & 0.004 & 14.7 \\
WC12 & Mean & 0.028 & 1.603 & 0.112 & 0.373 & 53.4 \\
& SD & 0.004 & 0.007 & 0.038 & 0.006 & 4.0 \\
WC13 & Mean & 0.026 & 1.605 & 0.098 & 0.373 & 55.4 \\
& SD & 0.006 & 0.005 & 0.034 & 0.004 & 0.2 \\
WC14 & Mean & 0.027 & 1.604 & 0.110 & 0.373 & 55.1 \\
& SD & 0.005 & 0.007 & 0.039 & 0.004 & 0.7 \\
\hline
\end{tabular}

hydrologic conditions (at LW13) that were accounted for when we integrated together several modeling conditions in the inverse solutions, which were not accounted for by the earlier implementations of method 1 (Figures $4 \mathrm{~b}$ and 5b). A sample performance of the derived soil hydraulic parameters in simulating the near-surface soil moisture when used in forward simulations is shown in Figures 10a and 10b (for LW03). It is evident that the derived parameters are "effective" for all the modeling conditions used (groundwater (Figure 10a) and free drainage (Figure 10b)). Interesting to note is the narrower variability of the simulated soil moisture contents among the groundwater conditions in method 2 compared with method 1 (Figure 8a, top plot). This small variability suggests that the derived parameters in method 2 produced almost similar near-soil moisture contents across the spectrum of groundwater conditions used. This further supports the "effective" nature of the derived soil hydraulic parameters.

[38] However, remote sensing data are always corrupted with certain (e.g., retrieval algorithm, sensor accuracy, geoprojection) errors. To illustrate the potential of method 2 in including data errors to the inverse analysis, we used the in situ regional (average) soil moisture as a replicate for the ESTAR data (see sections 2.1 and 2.2.4; equations (7) and (8)). Usually, this is done by introducing a white noise (based on RS accuracy) to the original RS data to produce stochastic replicates. In equation (8), we gave equal weights to both the ESTAR and regional in situ soil moisture data. Table $2 \mathrm{~d}$ shows the derived soil hydraulic parameters (LW13) using method 2 under multidata analysis. LW13 was chosen for further analysis because as shown in Figure 8c

Table 4b. Derived Effective Soil Hydraulic Parameters for SMEX02 Fields WC11, WC12, WC13, and WC14 Using Method 1 Under Free Drainage Conditions

\begin{tabular}{|c|c|c|c|c|c|c|}
\hline & Statistics & $\begin{array}{c}\alpha \\
\left(\mathrm{cm}^{-1}\right)\end{array}$ & $\begin{array}{l}n \\
()\end{array}$ & $\left(\mathrm{cm}^{\theta_{\text {res }}} \mathrm{cm}^{-3}\right)$ & $\left(\mathrm{cm}^{\theta_{\text {sat }}} \mathrm{cm}^{-3}\right)$ & $\begin{array}{c}K_{\text {sat }} \\
\left(\mathrm{cm} \mathrm{d}^{-1}\right)\end{array}$ \\
\hline \multirow[t]{2}{*}{ WC11 } & Mean & 0.014 & 1.600 & 0.138 & 0.370 & 47.63 \\
\hline & $\mathrm{SD}$ & 0.003 & 0.008 & 0.003 & 0.000 & 9.52 \\
\hline \multirow[t]{2}{*}{ WC12 } & Mean & 0.011 & 1.593 & 0.109 & 0.373 & 55.112 \\
\hline & $\mathrm{SD}$ & 0.004 & 0.024 & 0.031 & 0.004 & 0.610 \\
\hline \multirow[t]{2}{*}{ WC13 } & Mean & 0.008 & 1.554 & 0.088 & 0.373 & 55.409 \\
\hline & SD & 0.002 & 0.053 & 0.026 & 0.003 & 0.396 \\
\hline \multirow[t]{2}{*}{ WC14 } & Mean & 0.009 & 1.574 & 0.105 & 0.373 & 54.871 \\
\hline & SD. & 0.002 & 0.038 & 0.035 & 0.003 & 0.795 \\
\hline
\end{tabular}



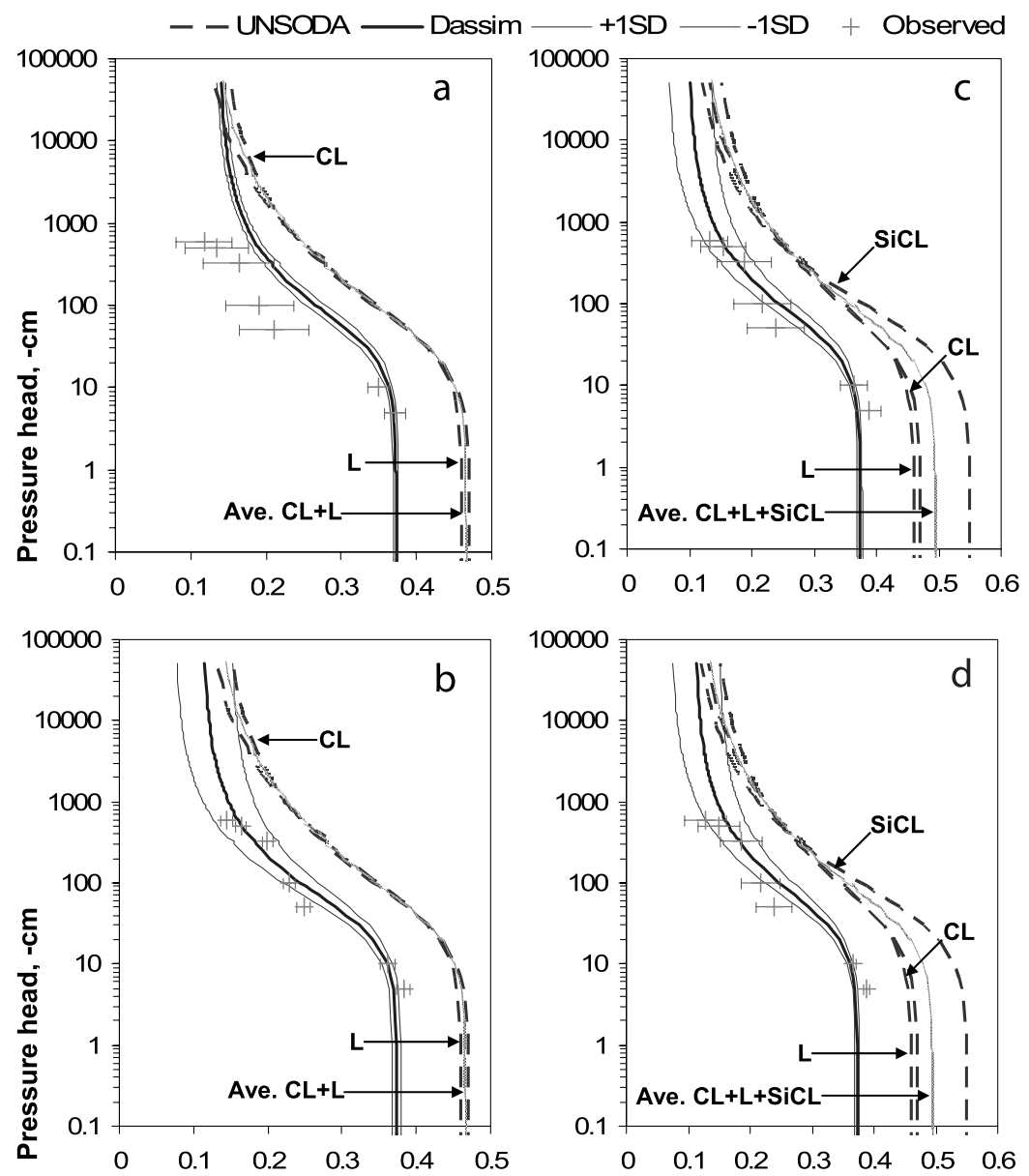

Soil moisture, $\mathrm{cm}^{3} \mathrm{~cm}^{-3}$

Figure 12. Comparison of derived $\theta(h)$ (Dassim) from method 1 under groundwater conditions, UNSODA and observed (field average and spread) soil water retention curves for the selected fields at SMEX02 site: (a) WC11 $(\mathrm{N}=6)$, (b) WC12 $(\mathrm{N}=4)$, (c) WC13 $(\mathrm{N}=6)$, and (d) WC14 $(\mathrm{N}=3) . \mathrm{N}$ indicates the number of samples; $\mathrm{L}$ is loam, CL is clay loam, and SiCL is silty clay loam.

it appears that the RS soil moisture underestimates the regional in situ soil moisture. Hence the soil hydraulic parameters derived earlier from method 2 only represent the information contained from remote sensing data. By including the regional soil moisture as additional conditioning criteria, we may be able to find a more robust soil hydraulic parameter set for LW13. The performance of this parameter set (Table 2d; Figure 7) is illustrated in Figures 11a and $11 \mathrm{~b}$. It appears that the multidata analysis improved the replication of the regional in situ soil moisture. The spreads of the simulated soil moistures (Figures 11a and 11b) have also increased because both the information contents of the data (ESTAR and regional in situ) are being used in conditioning the soil hydraulic parameters (compare Table 2c and 2d; LW13). It also shows in Figure 7 that in order to simulate better the regional in situ soil moisture, the soil hydraulic function has to be slightly wetter (see Figure 6b). Note, however, that under the combined modeling conditions used, the regional in situ data were more favored by method 2 than the remote sensing data in the multidata analysis (Figures 11a and 11b). In operational mode, Figures 11a and 11b ombined usually to produce consolidated simulation results that can account for both modeling and data errors.

\subsubsection{Validation}

[39] Methods 1 and 2, and the multidata variant of method 2, were validated using laboratory and field measured soil hydraulic data from the SGP97 fields and by texture-based data from UNSODA database [Leij et al., 1999]. Figures 4-7 show the comparisons of the derived soil hydraulic functions with laboratory measurements and UNSODA. Tables $3 \mathrm{a}-3 \mathrm{~d}$, on the other hand, show the correlations (R), mean bias error (MBE), and root mean square error (RMSE) of the simulated and observed soil moisture contents (RS and regional in situ (defined as ground)). The simulated versus RS columns serve as our calibration (although in the forward modeling the parameter sets from one modeling condition were applied to all modeling conditions used, akin to cross validation); while the simulated versus soil cores serve as full validation of the derived soil hydraulic parameters.

\subsubsection{Method 1 Under Groundwater Conditions}

[40] Except for LW13, the observed average (regional) soil water retention curves (see equation (9)) are well 

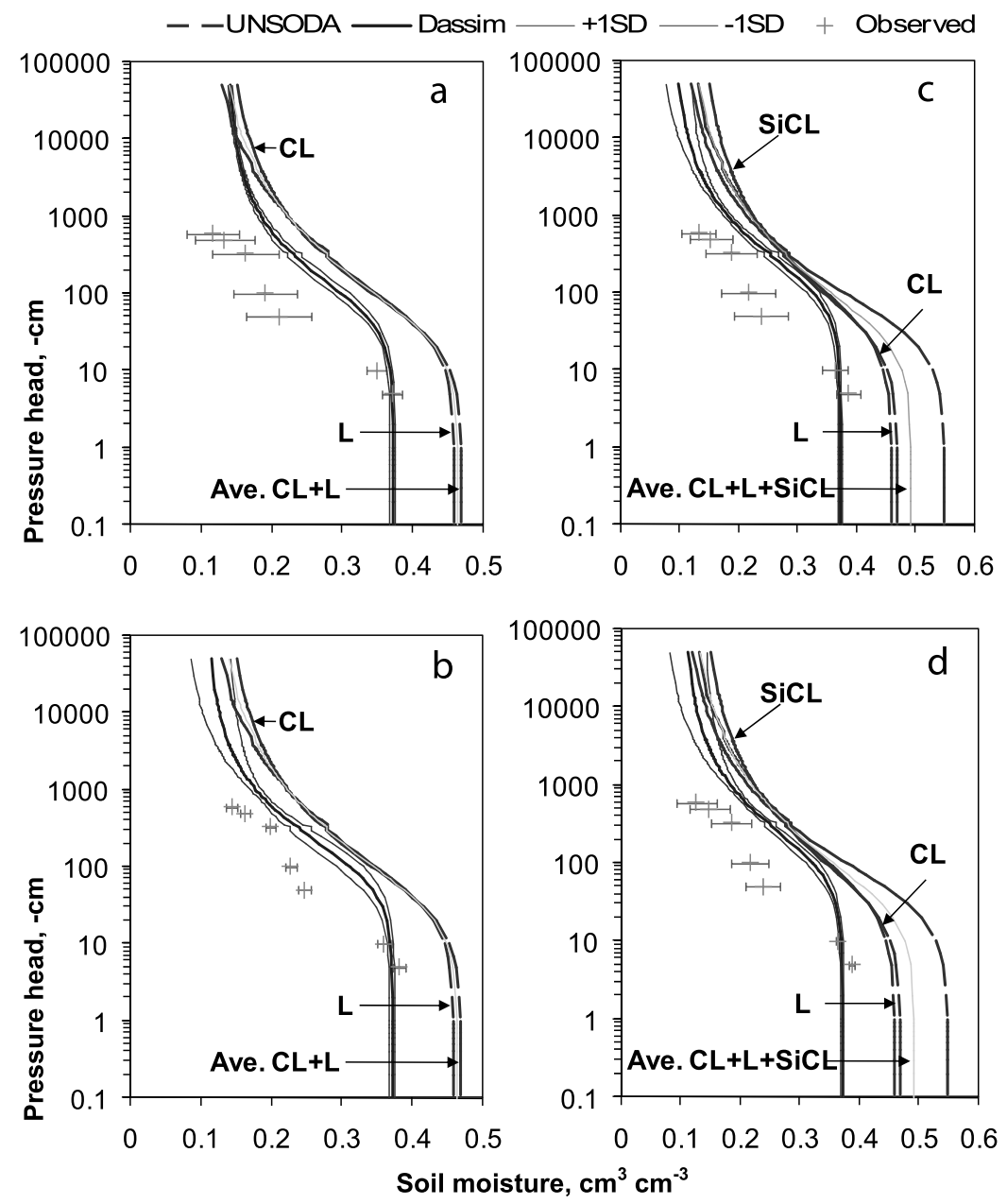

Figure 13. Comparison of derived $\theta(h)$ (Dassim) from method 1 under free drainage conditions, UNSODA and observed (field average and spread) soil water retention curves for the selected fields at SMEX02 site: (a) WC11 $(\mathrm{N}=6)$, (b) WC12 $(\mathrm{N}=4)$, (c) WC13 $(\mathrm{N}=6)$, and (d) $\mathrm{WC1} 14(\mathrm{~N}=3)$. $\mathrm{N}$ indicates the number of samples; $\mathrm{L}$ is loam, CL is clay loam, and SiCL is silty clay loam.

represented by the inverse modeling estimates (Dassim). Interesting to note is that the UNSODA data also represented well the observed values, suggesting that under the current conditions (physical/hydroclimatic) of the SGP97 fields, texture-based soil hydraulic data could perhaps be used to estimate the regional soil hydraulic properties of the fields. The SGP97 fields are composed mostly of undisturbed soils since there were limited agricultural activities (major land use is grassland) observed in the area. $K_{\text {sat }}$ values also correspond well within the UNSODA range (for loam, silt loam, sandy loam) [Leij et al., 1999] and the observed (regional) field data [Ines and Mohanty, 2008b]. In Table $3 \mathrm{a}$, the $\mathrm{R}_{\text {calibration }}$ ranges from 0.73 to 0.86 while the $\mathrm{R}_{\text {validation }}$ ranges from 0.47 to 0.84 when parameters derived under groundwater conditions are applied under groundwater conditions. The $\mathrm{MBE}_{\text {validation }}$ (and $\mathrm{RMSE}_{\text {validation}}$ ) of LW13 field showed an underestimation of the regional in situ soil moisture contents. It is noteworthy that the correlations decreased (both in calibration and validation modes) when these (groundwater based) parameters were applied under free drainage conditions. The bias is still evident in the case of LW13 field.

\subsubsection{Method 1 Under Free Drainage Conditions}

[41] Evidently, based on our previous observations (section 3.1.1) the correlations and errors (see Table 3b) of the simulated and observed soil moisture contents (both in calibration and validation modes) are better when the parameters derived under free drainage conditions are applied under free drainage lower boundary conditions in the forward modeling with the exception of LW21, suggesting that in this field, groundwater lower boundary conditions might be better applied. Except for LW21, the parameters derived under free drainage conditions produced wetter soil moisture (see MBE in Table 3b) when they are applied under groundwater conditions. The derived soil hydraulic properties appear to have higher water holding capacity than expected (see Figure 5).

\subsubsection{Method 2 Under Both Groundwater and Free} Drainage Conditions

[42] Usually at the footprint scale, we do not know exactly what the appropriate modeling conditions to be used for our forward/inverse modeling. In method 2, this uncertainty is accounted for by including many initial and lower boundary conditions in the analysis simultaneously. 

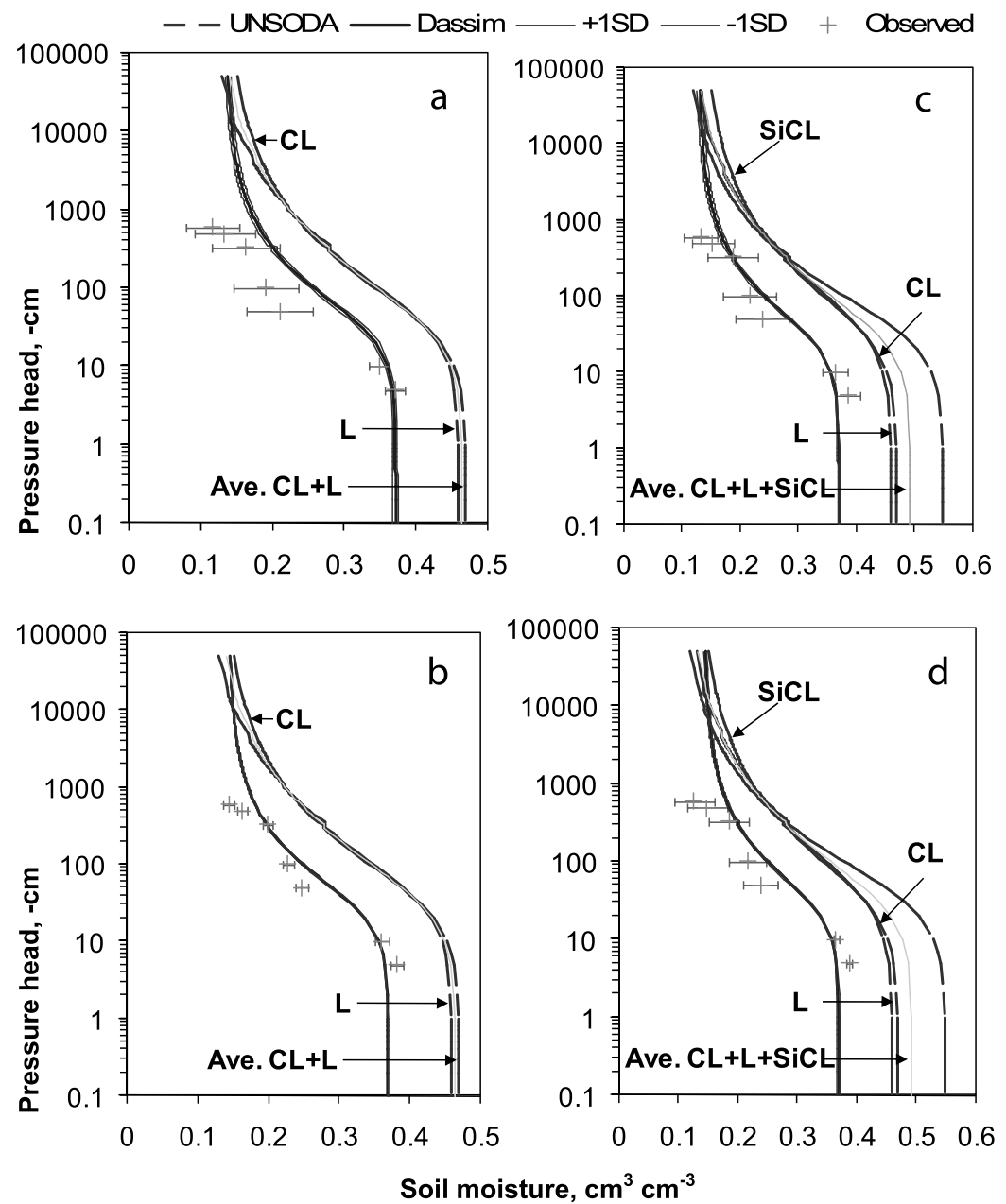

Figure 14. Comparison of derived $\theta(h)$ (Dassim) from method 2 (i.e., under all groundwater and free drainage conditions), UNSODA and observed (field average and spread) soil water retention curves for the selected fields at SMEX02 site: (a) WC11 ( $\mathrm{N}=6)$, (b) WC12 ( $=4)$, (c) WC13 ( $=6$ ), and (d) WC14 $(\mathrm{N}=3)$. $\mathrm{N}$ indicates the number of samples; $\mathrm{L}$ is loam, CL is clay loam, and SiCL is silty clay loam.

Table 3c shows the robustness of the derived soil hydraulic parameters applied under groundwater and free drainage conditions, respectively. Note the comparable correlations and errors (MBE and RMSE) of the simulated and observed soil moisture contents under calibration and validation mode. These results appear also to be more robust than those shown in Tables 3a-3b (see also Figures 4 and 6), although the negative bias (validation) of the simulated soil moisture is still apparent in LW13 field, suggesting that the simulated values underpredict the regional in situ data.

\subsubsection{Method 2 With Multidata Analysis}

[43] If we consider both the ESTAR and regional in situ soil moisture data in the parameter estimation, we can see that the errors (MBE and RMSE) between simulated and ground values were reduced considerably, suggesting that the regional in situ data are now well represented. However, the errors between the simulated and ESTAR values have increased relatively (see Table 3d, LW13 and SGP97). Note that both data sets were given the same weights in the inverse modeling. The correlations remained strong in both groundwater and free drainage conditions.

\subsection{SMEX02 Sites, Iowa}

\subsubsection{Effective Soil Hydraulic Properties and Soil Moisture for Selected SMEX02 Fields}

[44] Tables $4 \mathrm{a}$ and $4 \mathrm{~b}$ also show the derived soil hydraulic parameters for the selected SMEX02 fields WC11, WC12, WC13, and WC14 using method 1 under groundwater (Table 4a) and free drainage (Table 4b) conditions, respectively. The general trend that the soil hydraulic properties derived under free drainage conditions are wetter as compared with those derived under groundwater conditions is still evident (Tables 4a and 4b; Figures 12 and 13; see also Figures 14 and 15). Note, however, that it is only now the shape parameter $\alpha$ that contributed to this wetness. All the other soil hydraulic parameters are consistently comparable in both the free drainage and groundwater scenarios (Tables 4a and 4b). Figures 16a-16d also show the performance of the derived soil hydraulic parameters under groundwater conditions (method 1) in simulating the nearsurface soil moisture dynamics of the selected SMEX02 fields. It is generally observed that the soil hydraulic parameters derived under groundwater conditions are also applicable under free drainage conditions, consistent with 


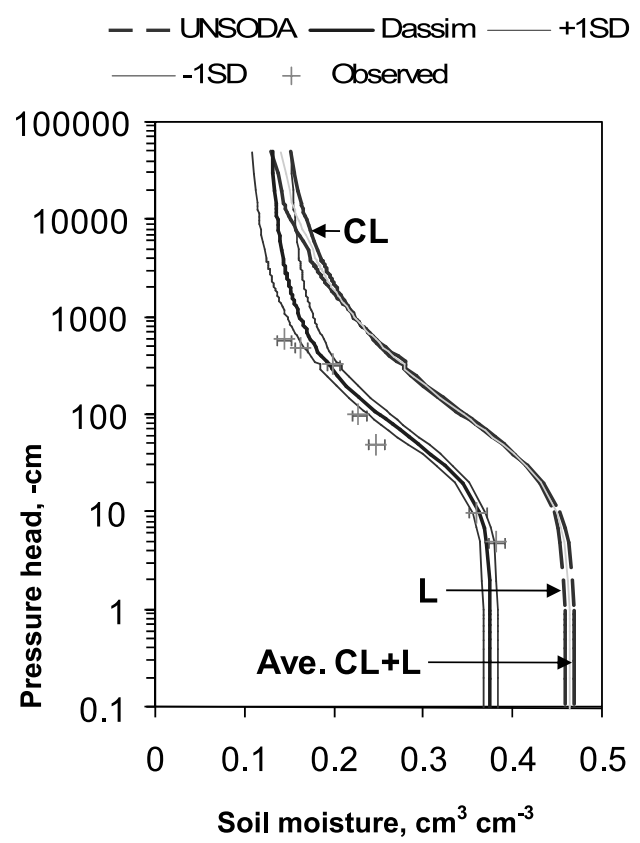

Figure 15. Comparison of derived $\theta(h)$ (Dassim) from method 2 under multidata analysis, UNSODA and observed (field average and spread) soil water retention curves for the WC12 $(\mathrm{N}=4)$ field at SMEX02 site. $\mathrm{N}$ indicates the number of samples; L is loam, SL is sandy loam, and SiL is silt loam.

the observations made in SGP97 results. Except for WC12 and WC14 (to some extent) the derived parameters consistently represented well the observed regional in situ soil moisture data. Interesting to note is the spread of the soil moisture simulated under free drainage conditions using groundwater condition-derived parameters (Figures 16a-16d, bottom plots), in which only WC11 has now the narrowest soil moisture variability. This response is attributed to the smaller variability of the derived residual soil moisture contents in WC11 compared with WC12, WC13, and WC14 (Table 4a; Figure 12). As in SGP97, the derived soil hydraulic parameters in SMEX02 for method 1 with free drainage conditions are generally applicable only to free drainage lower boundary conditions (Figure 17a). They produced wetter soil moisture contents when applied under groundwater conditions (i.e., $100-200 \mathrm{~cm}$ from the soil surface) (Figure 17b).

[45] Following the argument of deriving "effective" parameters applicable for all modeling conditions considered, we applied method 2 (section 2.1) to the selected SMEX02 fields. Evidently, the variability of the derived soil hydraulic parameters also decreased (Table 4c; Figure 14) since we need to satisfy all the modeling conditions used. As a result, the soil hydraulic parameters are all applicable to both groundwater and free drainage conditions (Figure 18). It is evident from both the study regions that if we consider an ensemble of modeling conditions collectively in our inverse modeling, we can arrive at a set of soil hydraulic parameters that are robust and effective at the footprint scale (see Figure 10 and Figure 18).

[46] Furthermore, we also applied method 2 in its multidata variant to WC12 field (see Table 2d). The multidata variant accounts for multiple sources of information for the inverse modeling in addition to the common features of method 2. In this case, we used both the PSR and regional in situ soil moisture as conditioning data for the inverse modeling in which we gave equal weights to the data sets (see equations (7) and (8)). The derived parameters in Table $2 \mathrm{~d}$ are comparable with Table $4 \mathrm{c}$, with only the variability being relatively increased because of the two sources of information used in the inverse analysis (Figure 15 versus Figure 14b). If we examine, though, how the derived parameters faired in both the PSR and regional in situ soil moisture data, we observe that under the combinations of modeling conditions used we could not replicate the regional in situ soil moisture data (Figure 19). Evidently, the inverse modeling favored more the information content of the remote sensing data with the given ensemble of modeling conditions. There could be several possible reasons for this result: Either the remote sensing data better captured the regional dynamics of the pixel than the measured regional in situ data, or the combinations of modeling conditions and other model assumptions used in the inverse modeling are not adequate to represent well the dynamics of WC12 field. Note, however, that even though we replicated well the regional soil hydraulic properties (Figure 15) from the inversion of remote sensing data, the soil moisture dynamics is always dependent on the modeling conditions (initial/boundary conditions) used in the simulations as discussed above.

\subsubsection{Validation}

[47] We also validated the results of method 1 and method 2 (with its multidata variant) in SMEX02 region using measured soil hydraulic properties, soil moisture time series, and texture-based information from UNSODA. Tables $5 \mathrm{a}-5 \mathrm{c}$ shows the calibration-validation (see section 3.1.2) performances of the derived soil hydraulic parameters for WC11, C12, WC13, and WC14.

\subsubsection{Method 1 Under Groundwater Conditions}

[48] Except for WC12, the correlations and errors between the simulated and observed soil moisture contents under calibration and validation modes are reasonably good (Table 5a). The robustness of the derived parameters applied in free drainage conditions is also evident. In the validation mode, the simulated soil moisture in WC12 overestimates considerably the regional in situ soil moisture data.

[49] Figure 12 shows the performance of the derived soil hydraulic parameters as regards to matching the observed regional soil hydraulic characteristics of the selected fields. It is interesting to note that the texture-based UNSODA curves are not even close to the measured regional soil hydraulic properties, whereas derived parameters by inverse modeling matched them reasonably well. Unlike in SGP97 fields wherein the soils are generally undisturbed, SMEX02 fields are agricultural areas and the soils were subject to agricultural activities. These results mainly underscore the importance of using actual field data to estimate the soil hydraulic properties of a study area. Also, because SMEX02 region has a high level of agricultural activities, inducing greater surface macroporosity due to tillage, root decay, and earth worm activities, our estimates of $\mathrm{K}_{\text {sat }}$ (Table 4a) are much lower than the laboratory measured $\mathrm{K}_{\text {sat }}$ values (B. P. Mohanty, 2006, unpublished data, http://vadosezone.tamu.edu). 

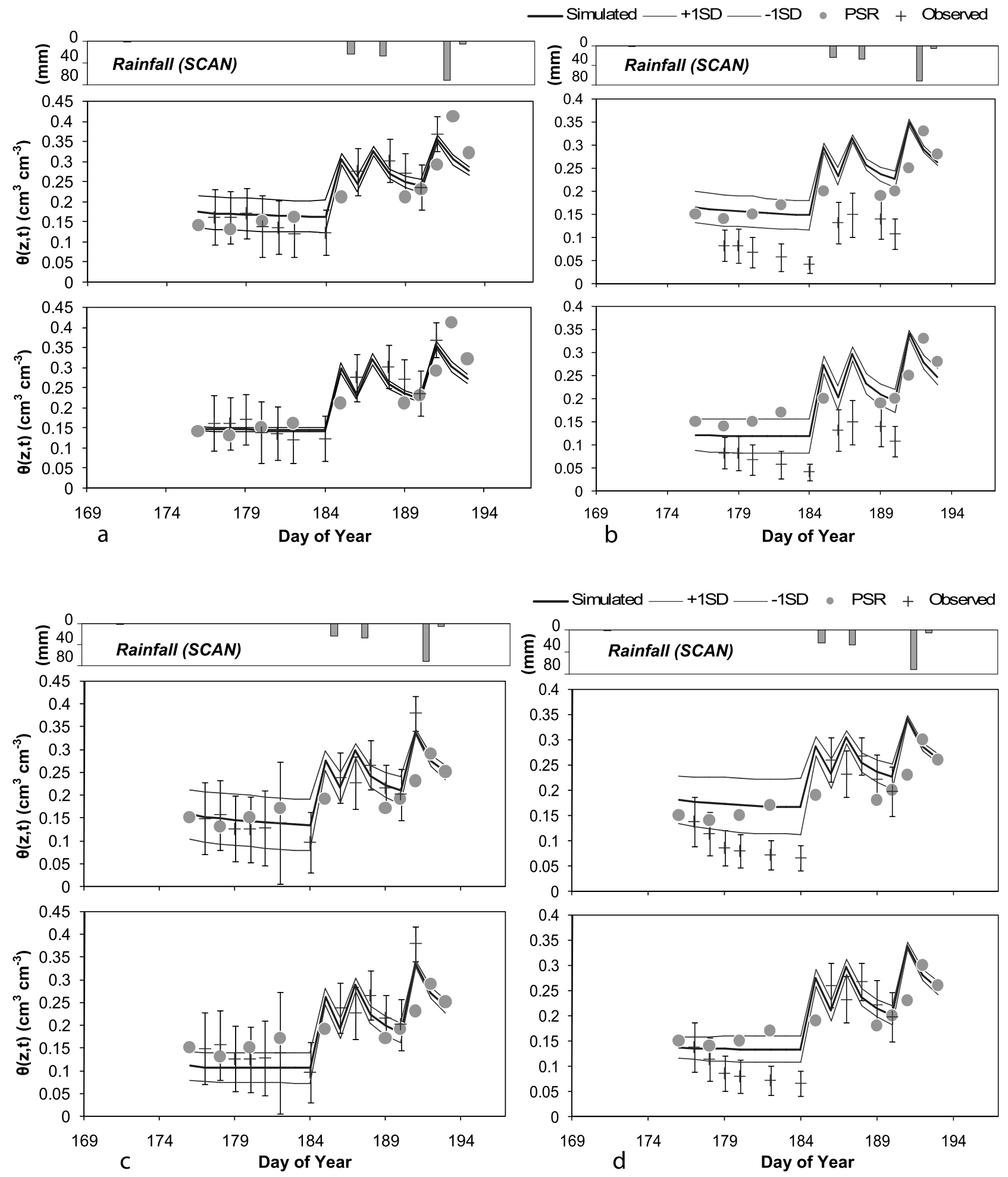

Figure 16. Simulated and cross-validated near-surface soil moisture $(z=0-5 \mathrm{~cm})$ using method 1 under groundwater conditions versus polarimetric scanning radiometer (PSR) and observed areal-average (with spread) soil moisture during SMEX02: (a) WC11 ( $\mathrm{N}=91)$, (b) WC12 ( $=132$ ), (c) WC13 ( $\mathrm{N}=140)$, and $(\mathrm{d}) \mathrm{WC} 14(\mathrm{~N}=94)$. $\mathrm{N}$ indicates the number of samples. Top panels are applied to all groundwater conditions; bottom panels are applied to all free drainage conditions.

\subsubsection{Method 1 Under Free Drainage Conditions}

[50] Table 5b shows the calibration-validation performance of the derived soil hydraulic parameters under free drainage condition using method 1 . The correlations and errors between observed and simulated soil moisture are all good when applied in free drainage lower boundary con- 


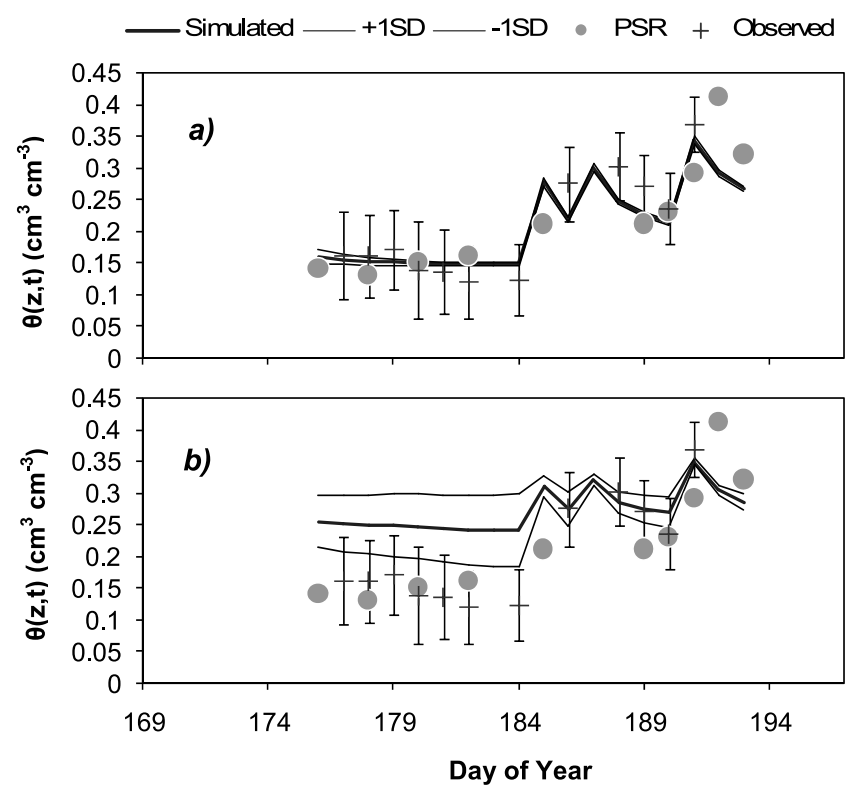

Figure 17. Sample results of simulated and crossvalidated near-surface soil moisture $(z=0-5 \mathrm{~cm})$ using method 1 under free drainage conditions versus PSR and observed areal-average (with spread) soil moisture at WC11 $(\mathrm{N}=91)$ during SMEX02: (a) applied to all free drainage conditions and (b) applied to all groundwater conditions. $\mathrm{N}$ indicates the number of samples.

ditions. Although the correlations of the simulated and observed soil moisture (in calibration and validation modes) are also good (acceptable) when they are applied under groundwater conditions, the errors (MBE and RMSE) are considerable especially under the validation mode. As shown in Figure 13, the derived soil hydraulic functions are generally wetter than expected.

\subsubsection{Method 2 Under Both Groundwater and Free Drainage Conditions}

[51] The calibration-validation performance of the derived soil hydraulic parameters under this method is given in Table 5c. It is clear that the derived parameters are robust among the modeling conditions used in both calibration and validation mode. The correlations and errors between observed and simulated soil moisture values are generally good except for WC12 field. Figure 14 also shows that

Table 4c. Derived Effective Soil Hydraulic Parameters for SMEX02 Fields WC11, WC12, WC13, and WC14 Using Method 2 (Under All Groundwater and Free Drainage Conditions, Collectively)

\begin{tabular}{ccccccc}
\hline & & $\begin{array}{c}\alpha \\
\end{array}$ & $\begin{array}{c}n \\
(\mathrm{~cm})\end{array}$ & $\begin{array}{c}\theta_{\text {res }} \\
\left(\mathrm{cm}^{3} \mathrm{~cm}^{-3}\right)\end{array}$ & $\begin{array}{c}\theta_{\text {sat }} \\
\left(\mathrm{cm}^{3} \mathrm{~cm}^{-3}\right)\end{array}$ & $\begin{array}{c}K_{\text {sat }} \\
\left(\mathrm{cm} \mathrm{d}^{-1}\right)\end{array}$ \\
\hline WC11 & Mean & 0.028 & 1.579 & 0.136 & 0.373 & 21.040 \\
& SD & 0.003 & 0.031 & 0.003 & 0.003 & 8.548 \\
$\mathrm{WC12}$ & Mean & 0.032 & 1.605 & 0.145 & 0.370 & 51.902 \\
& SD & 0.001 & 0.005 & 0.001 & 0.000 & 3.833 \\
WC13 & Mean & 0.032 & 1.603 & 0.130 & 0.370 & 55.102 \\
& SD & 0.001 & 0.006 & 0.005 & 0.001 & 0.789 \\
WC14 & Mean & 0.032 & 1.604 & 0.144 & 0.371 & 55.423 \\
& SD & 0.001 & 0.007 & 0.003 & 0.002 & 0.201
\end{tabular}

the variability of the derived soil hydraulic functions is small and well comparable with the observed regional soil hydraulic properties.

\subsubsection{Method 2 With Multidata Analysis}

[52] Under multidata analysis, we failed to replicate well the regional in situ soil moisture data in the validation mode for WC12. Table 3d shows that the correlations are good but the biases (errors) between the simulated and the ground data are considerable. Evidently, the simulated soil moisture overestimated the regional in situ soil moisture data but it follows well the dynamics of the PSR soil moisture data (Figure 19). As shown in Figure 15, the derived soil hydraulic parameters capture the observed regional hydrologic characteristics of the field. If we assume that the remote sensing data are adequate, then we hypothesized that the ensemble of modeling conditions and other modeling assumptions used in the inverse modeling may not be adequate to represent well the regional dynamics of soil moisture in this field. We should note, however, that all measured data, whether remote sensing or ground-based, are subject to errors, and hence we should not disregard the fact that there could be errors incurred in the ground-based soil moisture data in this particular field.

\section{Summary and Conclusions}

[53] In this paper, we presented the results of the newly developed inverse modeling-based near-surface soil moisture assimilation scheme [see Ines and Mohanty, 2008a] to quantify effective soil hydraulic parameters at the footprints of two airborne RS passive microwave sensors, ESTAR and

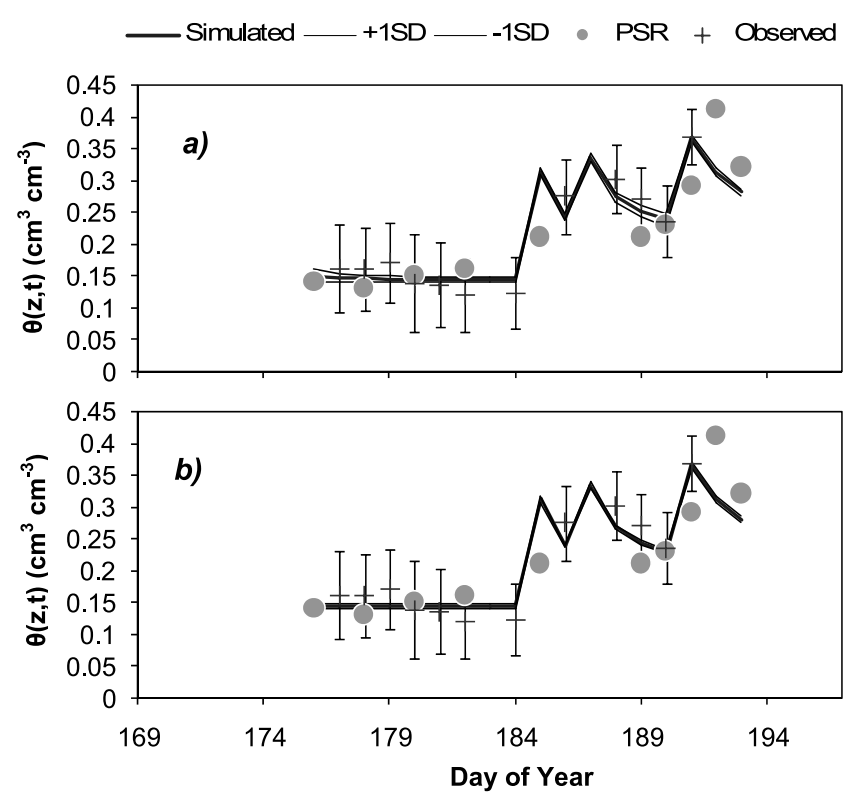

Figure 18. Sample results of simulated and crossvalidated near-surface soil moisture $(z=0-5 \mathrm{~cm})$ using method 2 (i.e., under all groundwater and free drainage conditions, collectively) versus PSR and observed arealaverage (with spread) soil moisture at WC11 ( $\mathrm{N}=91)$ during SMEX02: (a) applied to all groundwater conditions and (b) applied to all free drainage conditions. $\mathrm{N}$ indicates the number of samples. 

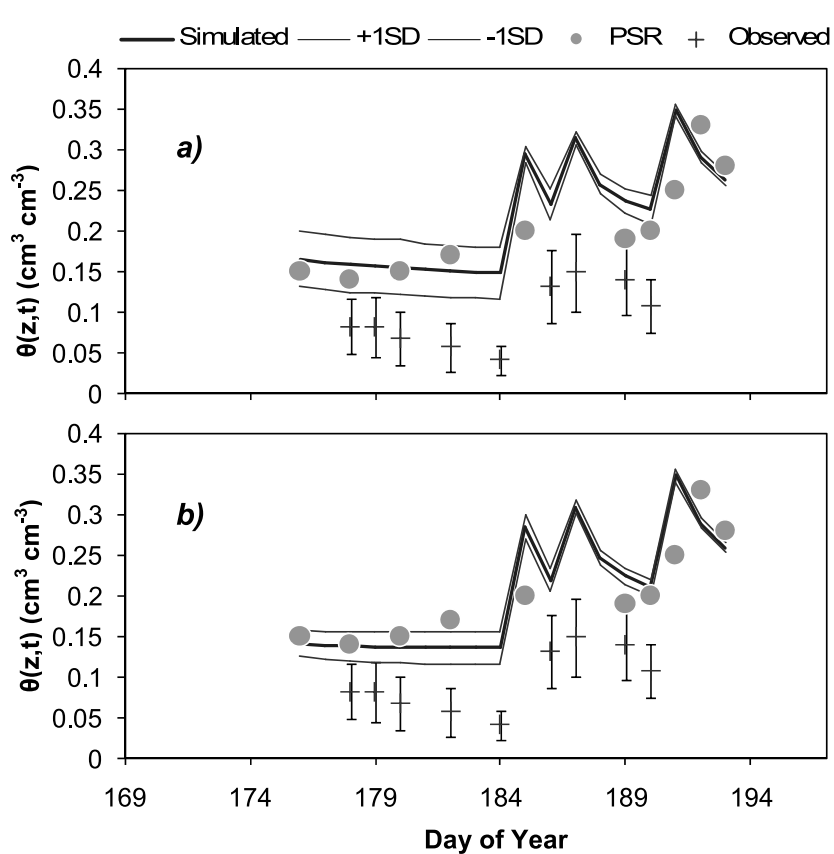

Figure 19. Sample results of simulated and crossvalidated near-surface soil moisture $(z=0-5 \mathrm{~cm})$ using method 2 under multidata analysis versus PSR and observed areal-average (with spread) soil moisture at $\mathrm{WC12}(\mathrm{N}=$ 132) during SMEX02: (a) applied to all groundwater conditions and (b) applied to all free drainage conditions. $\mathrm{N}$ indicates the number of samples.

PSR. We conducted the experiments at three fields/RS footprints in Oklahoma and four in Iowa during the SGP97 and SMEX02 campaigns, respectively. The near-surface soil moisture assimilation procedure includes the use of time series of near-surface soil moisture data to invert a 1-D physically based soil-water-atmosphere-plant model SWAP with a modified-microGA for estimating the effective soil hydraulic parameters of a footprint. Uncertainties in the solutions were examined in two ways: (1) by solving the inverse problem under various combinations of modeling conditions in a respective way; and (2) inverse solutions determined for modeling conditions in a collective way aimed at finding the robust solutions for all the ensembles.

Table 5a. Performance of Method 1 Under Groundwater Conditions at SMEX02 Sites

\begin{tabular}{|c|c|c|c|c|c|c|}
\hline \multirow[b]{2}{*}{ Fields } & \multicolumn{3}{|c|}{ Simulated Versus RS } & \multicolumn{3}{|c|}{ Simulated Versus Ground } \\
\hline & $\mathrm{R}$ & MBE & RMSE & $\mathrm{R}$ & MBE & RMSE \\
\hline \multicolumn{7}{|c|}{ Applied to All Groundwater Conditions } \\
\hline WC11 & 0.78 & 0.015 & 0.056 & 0.97 & 0.005 & 0.026 \\
\hline WC12 & 0.76 & 0.022 & 0.045 & 0.92 & 0.102 & 0.095 \\
\hline WC13 & 0.76 & 0.023 & 0.048 & 0.93 & 0.006 & 0.028 \\
\hline WC14 & 0.74 & 0.036 & 0.053 & 0.88 & 0.050 & 0.066 \\
\hline \multicolumn{7}{|c|}{ Applied to All Free Drainage Conditions } \\
\hline WC11 & 0.80 & 0.001 & 0.052 & 0.97 & -0.012 & 0.026 \\
\hline WC12 & 0.79 & -0.005 & 0.047 & 0.90 & 0.071 & 0.078 \\
\hline WC13 & 0.79 & -0.001 & 0.051 & 0.93 & -0.022 & 0.036 \\
\hline WC14 & 0.77 & 0.013 & 0.047 & 0.87 & 0.021 & 0.044 \\
\hline
\end{tabular}

Table 5b. Performance of Method 1 Under Free Drainage Conditions at SMEX02 Sites

\begin{tabular}{|c|c|c|c|c|c|c|}
\hline \multirow[b]{2}{*}{ Fields } & \multicolumn{3}{|c|}{ Simulated Versus RS } & \multicolumn{3}{|c|}{ Simulated Versus Ground } \\
\hline & $\mathrm{R}$ & MBE & RMSE & $\mathrm{R}$ & MBE & RMSE \\
\hline \multicolumn{7}{|c|}{ Applied to All Groundwater Conditions } \\
\hline WC11 & 0.69 & 0.053 & 0.086 & 0.92 & 0.059 & 0.079 \\
\hline WC12 & 0.61 & 0.088 & 0.101 & 0.82 & 0.190 & 0.191 \\
\hline WC13 & 0.49 & 0.118 & 0.125 & 0.83 & 0.120 & 0.136 \\
\hline WC14 & 0.56 & 0.095 & 0.104 & 0.72 & 0.126 & 0.143 \\
\hline \multicolumn{7}{|c|}{ Applied to All Free Drainage Conditions } \\
\hline WC11 & 0.81 & -0.003 & 0.051 & 0.96 & -0.014 & 0.031 \\
\hline WC12 & 0.80 & 0.004 & 0.038 & 0.91 & 0.083 & 0.085 \\
\hline WC13 & 0.79 & 0.012 & 0.038 & 0.94 & -0.008 & 0.030 \\
\hline WC14 & 0.79 & 0.013 & 0.041 & 0.87 & 0.021 & 0.047 \\
\hline
\end{tabular}

A multidata variant of method 2 was presented to account for both data and modeling errors in the inverse analysis. We validated the soil hydraulic properties results using intensive in situ/laboratory measurements conducted at the respective fields, and data sets available from the literature with similar soil textures (UNSODA database). The performance of the derived effective soil hydraulic parameters and simulated near-surface soil moisture in each study pixel were also evaluated against RS and ground based soil moisture data.

[54] The results clearly showed the promising potentials of near-surface RS soil moisture data combined with inverse modeling for determining average soil hydrologic properties at the footprint scale. Our cross validation showed that parameters derived by method 1 under groundwater conditions are applicable also for free-draining conditions. Parameters derived under free-draining conditions, however, generally produced too wet near-surface soil moisture when applied under groundwater conditions. Method 2, on the other hand, produced robust parameter sets applicable for all modeling conditions used. In this study, we conclude that inverse modeling of RS soil moisture data is a promising approach for large-scale parameter estimation. Nevertheless, the derived effective soil hydraulic parameters are subject to the uncertainties of remotely sensed soil moisture data and from the assumptions used in the soil-water-atmosphere-plant modeling. Method 2 provided a flexible framework for

Table 5c. Performance of Method 2 (Under All Groundwater and Free Drainage Conditions, Collectively) at SMEX02 Sites

\begin{tabular}{|c|c|c|c|c|c|c|}
\hline \multirow[b]{2}{*}{ Fields } & \multicolumn{3}{|c|}{ Simulated Versus RS } & \multicolumn{3}{|c|}{ Simulated Versus Ground } \\
\hline & $\mathrm{R}$ & $\mathrm{MBE}$ & RMSE & $\mathrm{R}$ & $\mathrm{MBE}$ & RMSE \\
\hline \multicolumn{7}{|c|}{ Applied to All Groundwater Conditions } \\
\hline WC11 & 0.79 & 0.009 & 0.054 & 0.98 & -0.007 & 0.019 \\
\hline WC12 & 0.76 & 0.021 & 0.048 & 0.91 & 0.102 & 0.106 \\
\hline WC13 & 0.76 & 0.025 & 0.051 & 0.93 & 0.008 & 0.029 \\
\hline WC14 & 0.74 & 0.029 & 0.052 & 0.89 & 0.042 & 0.056 \\
\hline \multicolumn{7}{|c|}{ Applied to All Free Drainage Conditions } \\
\hline WC11 & 0.80 & 0.006 & 0.054 & 0.97 & -0.010 & 0.022 \\
\hline WC12 & 0.78 & 0.016 & 0.046 & 0.90 & 0.097 & 0.101 \\
\hline WC13 & 0.78 & 0.019 & 0.049 & 0.92 & 0.002 & 0.029 \\
\hline WC14 & 0.76 & 0.024 & 0.050 & 0.87 & 0.035 & 0.053 \\
\hline
\end{tabular}


accounting these sources of uncertainties in the inverse estimation of large-scale soil hydraulic properties.

[55] There are some observed weaknesses of the nearsurface soil moisture assimilation method used. Since it relies on the RS soil moisture products, any uncertainties in RS data because of retrieval/calibration/geoprojection can directly propagate to the derived soil hydraulic parameters at the pixel-scale. There is also an issue of the sensitivity of soil hydraulic parameters to the observed (temporal) RS data, and the fitness function used in the inverse analyses. The effectiveness of the derived soil hydraulic parameters is also affected by the uncertainties in the soil-wateratmosphere-plant model, and the inherent assumptions used in these simulations. Nevertheless, as this method defines the "effective" parameters, and as long as they reflect the large-scale dynamics, we can use them for large-scale hydrologic and climatic modeling efforts.

[56] Acknowledgments. This research was funded by NASA-GAPP grant NNG04GM35G. We would like to acknowledge the partial support of LANL-SAHRA, NASA (JPL, GSFC, THP), and NSF (CMG/DMS) grants for this work. We acknowledge the use of the USDA-ARS micronet data and SCAN data in the SGP97 and SMEX02 sites. We thank the editors and reviewers for helping us improve the quality of this paper.

\section{References}

Bindlish, R. (2004), SMEX02 Aircraft Polarimetric Scanning Radiometer (PSR) Tb data, digital media, Natl. Snow and Ice Data Cent., Boulder, Colo.

Chan-Hilton, A. B., and T. B. Culver (2000), Constraint handling for genetic algorithms in optimal remediation design, J. Water Resour. Plann. Manage., 126, 128-137, doi:10.1061/(ASCE)0733-9496(2000) 126:3(128).

Cieniawski, S. E., J. W. Eheart, and S. Ranjithan (1995), Using genetic algorithms to solve a multiobjective groundwater monitoring problem, Water Resour. Res., 31(2), 399-409.

Cosh, M. H., T. J. Jackson, R. Bindlish, and J. H. Prueger (2004), Watershed scale temporal and spatial stability of soil moisture and its role in validating satellite estimates, Remote Sens. Environ., 92, 427-435, doi:10.1016/j.rse.2004.02.016.

Crow, W. T., and E. F. Wood (2003), The assimilation of remotely sensed soil brightness temperature imagery into a land surface model using ensemble Kalman filtering: A case study based on ESTAR measurements during SGP97, Adv. Water Resour., 26, 137-149, doi:10.1016/S03091708(02)00088-X.

Crow, W. T., D. Ryu, and J. S. Famiglietti (2005), Upscaling of field-scale soil moisture measurements using a distributed land surface model, $A d v$. Water Resour., 28, 1-14, doi:10.1016/j.advwatres.2004.10.004.

Das, N. N., and B. P. Mohanty (2006), Root zone soil moisture assessment using remote sensing and vadose zone modeling, Vadose Zone J., 5, 296-307, doi:10.2136/vzj2005.0033.

Dunne, S., and D. Entekhabi (2005), An ensemble-based reanalysis approach to land data assimilation, Water Resour. Res., 41, W02013, doi:10.1029/2004WR003449

Entekhabi, D., H. Nakamura, and E. G. Njoku (1994), Solving the inverse problem for soil moisture and temperature profiles by sequential assimilation of multifrequency remotely sensed observations, IEEE Trans. Geosci. Remote Sens., 32(2), 438-448, doi:10.1109/36.295058.

Feddes, R. A., P. J. Kowalik, and H. Zarandy (1978), Simulation of Field Water Use and Crop Yield, Cent. for Agric. Publ., Wageningen, Netherlands.

Feddes, R. A., G. H. De Rooij, J. C. Van Dam, P. Kabat, and P. Droogers (1993a), Estimation of regional effective soil hydraulic parameters by inverse modeling, in Water Flow and Solute Transport in Soils, Adv. Ser. Agric. Sci. Ser, vol. 20, edited by D. Russo and G. Dagan, pp. $211-$ 233, Springer, Berlin.

Feddes, R. A., M. Menenti, P. Kabat, and W. G. M. Bastiaanssen (1993b), Is large-scale inverse modeling of unsaturated flow with areal average evaporation and surface soil moisture as estimated by remote sensing feasible?, J. Hydrol. Amsterdam, 143, 125-152, doi:10.1016/00221694(93)90092-N.
Goldberg, D. E. (1989), Genetic Algorithms in Search and Optimization and Machine Learning, Addison-Wesley, Boston, Mass.

Gwo, J.-P. (2001), In search of preferential flow paths in structured porous media using simple genetic algorithm, Water Resour. Res., 37(6), 15891601, doi:10.1029/2000WR900384.

Heathman, G. C., P. J. Starks, L. R. Ahuja, and T. J. Jackson (2003), Assimilation of surface soil moisture to estimate soil water content, J. Hydrol. Amsterdam, 279, 1 - 17, doi:10.1016/S0022-1694(03)00088-X.

Holland, J. H. (1975), Adaptation in Natural and Artificial Systems, Univ. of Mich. Press, Ann Arbor.

Ines, A. V. M., and P. Droogers (2002a), Inverse modelling in estimating soil hydraulic functions: A genetic algorithm approach, Hydrol. Earth Syst. Sci., 6, 49-65.

Ines, A. V. M., and P. Droogers (2002b), Inverse modeling to quantify irrigation system characteristics and operational management, Irrig. Drain. Syst., 16, 233-252, doi:10.1023/A:1021231132727.

Ines, A. V. M., and K. Honda (2005), On quantifying agricultural and water management practices from low spatial resolution RS data using genetic algorithms: A numerical study for mixed pixel environment, Adv. Water Resour., 28, 856-870, doi:10.1016/j.advwatres.2004.11.015.

Ines, A. V. M., and B. P. Mohanty (2008a), Near-surface soil moisture assimilation for quantifying effective soil hydraulic properties using genetic algorithm: 1. Conceptual modeling, Water Resour. Res., 44, W06422, doi:10.1029/2007WR005990.

Ines, A. V. M., and B. P. Mohanty (2008b), Near-surface soil moisture assimilation for quantifying effective soil hydraulic properties under different hydro-climatic conditions, Vadose Zone J., 7, 39-52, doi:10.2136/vzj2007.0048.

Ines, A. V. M., K. Honda, A. D. Gupta, P. Droogers, and R. S. Clemente (2006), Combining remote sensing-simulation modeling and genetic algorithm optimization to explore water management options in irrigated agriculture, Agric. Water Manage., 83, 221-232, doi:10.1016/j.agwat. 2005.12.006.

Jackson, T. J. (1993), Measuring surface soil moisture using passive microwave remote sensing, Hydrol. Processes, 7, 139-152, doi:10.1002/ hyp. 3360070205 .

Jackson, T. J. (2002), SMEX02 Soil Climate Analysis Network (SCAN) station 2031, Ames, Iowa, digital media, Natl. Snow and Ice Data Cent., Boulder, Colo.

Jackson, T. J., D. M. Le Vine, C. T. Swift, T. J. Schmugge, and F. R. Schiebe (1995), Large scale mapping of soil moisture using the ESTAR passive microwave radiometer in Washita '92, Remote Sens. Environ., 54, 27-37, doi:10.1016/0034-4257(95)00084-E.

Jackson, T. J., D. M. Le Vine, A. Y. Hsu, A. Oldak, P. J. Starks, C. T. Swift, J. D. Isham, and M. Hakan (1999), Soil moisture mapping at regional scales using microwave radiometry: The Southern Great Plains hydrology experiment, IEEE Trans. Geosci. Remote Sens., 37, 2136-2151, doi:10.1109/36.789610.

Jacobs, J. M., B. P. Mohanty, E. C. Hsu, and D. Miller (2004), SMEX02: Field scale variability, time stability and similarity of soil moisture, $R e-$ mote Sens. Environ., 92, 436-446.

Kostov, K. G., and T. J. Jackson (1993), Estimating profile soil moisture from surface layer measurement: A review, Proc. SPIE Int. Soc. Opt. Eng., 1941, 125-136, doi:10.1117/12.154681.

Krishnakumar, K. (1989), Microgenetic algorithms for stationary and nonstationary function optimization, SPIE Intell. Control Adapt. Syst., 1196, 289-296.

Leij, F. J., W. J. Alves, M. T. Van Genuchten, and J. R. Williams (1999), The UNSODA unsaturated soil hydraulic database, in Characterization and Measurement of the Hydraulic Properties of Unsaturated Porous Media, edited by M. T. Van Genuchten et al., pp. 1269-1281, Univ. of Calif., Riverside.

Margulis, S., D. McLaughlin, D. Enthekabi, and S. Dunne (2002), Land data assimilation and estimation of soil moisture using experiments from the Southern Great Plains 1997 Field Experiment, Water Resour. Res., 38(12), 1299, doi:10.1029/2001WR001114.

Michalewicz, Z. (1996), Genetic Algorithms + Data Structures = Evolution Programs, 3rd ed., Springer, New York.

Miller, B. L. (1997), Noise, sampling and efficient genetic algorithms, IlliGAL Rep. 97001, Ill. Genetic Algorithms Lab., Urbana-Champagne, Ill., May.

Miller, E. E., and R. D. Miller (1956), Physical theory of capillary flow phenomena, J. Appl. Phys., 27, 324-332, doi:10.1063/1.1722370.

Mohanty, B. P., and T. H. Skaggs (2001), Spatio-temporal evolution and time-stable characteristics of soil moisture within remote sensing foot- 
prints with varying soil, slope and vegetation, Adv. Water Resour., 24, 1051-1067, doi:10.1016/S0309-1708(01)00034-3.

Mohanty, B. P., and J. Zhu (2007), Effective soil hydraulic parameters in horizontally and vertically heterogeneous soils for steady-state land atmosphere interaction, J. Hydrometeorol., 8(4), 715-729, doi:10.1175/ JHM606.1.

Mohanty, B. P., J. S. Famiglietti, and T. H. Skaggs (2000), Evolution of soil moisture spatial structure in a mixed vegetation pixel during the Southern Great Plains 1997 (SGP97) Hydrology Experiment, Water Resour. Res., 36, 3675-3686, doi:10.1029/2000WR900258.

Mohanty, B. P., P. J. Shouse, D. A. Miller, and M. T. Van Genuchten (2002), Soil property database: Southern Great Plains 1997 Hydrology Experiment, Water Resour. Res., 38(5), 1047, doi:10.1029/ 2000WR000076.

Mualem, Y. (1976), A new model for predicting the hydraulic conductivity of unsaturated porous media, Water Resour. Res., 12, 513-522, doi:10.1029/WR012i003p00513.

Njoku, E. G., and D. Entekhabi (1996), Passive remote sensing of soil moisture, J. Hydrol. Amsterdam, 184(1-2), 101-130, doi:10.1016/ 0022-1694(95)02970-2.

Njoku, E. G., T. J. Jackson, V. Lakshmi, T. K. Chan, and S. V. Nghiem (2003), Soil moisture retrieval from AMSR-E, IEEE Trans. Geosci. Remote Sens., 41, 215-229, doi:10.1109/TGRS.2002.808243.

Oliveira, R., and D. P. Loucks (1997), Operating rules for multi reservoir systems, Water Resour. Res., 33, 839-852, doi:10.1029/96WR03745.

Peters-Lidard, C. D., D. M. Mocko, M. Garcia, J. A. Santanello, M. A Tischler, M. S. Moran, and Y. Wu (2008), Role of precipitation uncertainty in the estimation of hydrologic soil properties using remotely sensed soil moisture in a semiarid environment, Water Resour. Res. 44, W05S18, doi:10.1029/2007WR005884.

Reichle, R., D. B. McLaughlin, and D. Entekhabi (2001), Variational data assimilation of microwave radio brightness observations for land surface hydrologic applications, IEEE Trans. Geosci. Remote Sens., 39, $1708-$ 1718, doi:10.1109/36.942549.

Research Systems, Inc. (RSI) (2003), ENVI Version 3.6: The Environment for Visualizing Images, Boulder, Colo.

Ritzel, B., J. W. Eheart, and S. Ranjithan (1994), Using genetic algorithms to solve a multiobjective groundwater pollution containment problem, Water Resour. Res., 30, 1589-1603, doi:10.1029/93WR03511.

Savic, D., and S.-T. Khu (2005), Evolutionary computing in hydrological sciences, in Encyclopedia of Hydrological Sciences, vol. 2, Hydroinformatics, edited by M. G. Anderson, John Wiley, Hoboken, N. J.

Schmugge, T. J. (1998), Applications of passive microwave observations of surface soil moisture, J. Hydrol. Amsterdam, 212-213, 188-197, doi:10.1016/S0022-1694(98)00209-1.

Schmugge, T. J., W. P. Kustas, J. C. Ritchie, T. J. Jackson, and A. Rango (2002), Remote sensing in hydrology, Adv. Water Resour., 25, $1367-$ 1385, doi:10.1016/S0309-1708(02)00065-9.

Smalley, J. B., B. S. Minsker, and D. E. Goldberg (2000), Risk-based in situ bioremediation design using a noisy genetic algorithm, Water Resour. Res., 36, 3043-3052, doi:10.1029/2000WR900191.
Van Dam, J. C. (2000), Field-scale water flow and solute transport: SWAP model concepts, parameter estimation and case studies, Ph.D. thesis, Wageningen Univ., Wageningen, Netherlands.

Van Dam, J. C., J. Huygen, J. G. Wesseling, R. A. Feddes, P. Kabat, P. E. V. Van Waslum, P. Groenendjik, and C. A. Van Diepen (1997), Theory of SWAP version 2.0: Simulation of water flow and plant growth in the soilwater-atmosphere-plant environment, Tech. Doc. 45, Wageningen Agric. Univ., Wageningen, Netherlands.

Van Genuchten, M. T. (1980), A closed-form equation foe predicting the hydraulic conductivity of unsaturated soils, Soil Sci. Soc. Am. J., 44, 892-898.

Vrugt, J. A., J. W. Hopmans, and J. Šimůnek (2001), Calibration of a twodimensional root water uptake model, Soil Sci. Soc. Am. J., 65, $1027-$ 1037.

Walker, J. P., G. R. Willgoose, and J. D. Kalma (2001), One-dimensional soil moisture profile retrieval by assimilation of near-surface observations: A comparison of retrieval algorithms, Adv. Water Resour., 24, 631-650, doi:10.1016/S0309-1708(00)00043-9.

Wang, Q. J. (1991), The genetic algorithm and its application to calibrating conceptual rainfall-runoff models, Water Resour. Res., 27, 2467-2471, doi:10.1029/91WR01305.

Wardlaw, R., and M. Sharif (1999), Evaluation of genetic algorithms for optimal reservoir system operation, J. Water Resour. Plann. Manage., 125, 25-33, doi:10.1061/(ASCE)0733-9496(1999)125:1(25).

Wood, E. F. (1994), Scaling, soil moisture and evapotranspiration in runoff models, Adv. Water Resour., 17, 25-34, doi:10.1016/03091708(94)90021-3.

Wu, J., C. Zheng, C. Chein, and L. Zheng (2006), A comparative study of Monte Carlo simple genetic algorithm and noisy genetic algorithm for cost-effective sampling network design under uncertainty, Adv. Water Resour., 29, 899-911, doi:10.1016/j.advwatres.2005.08.005.

Zhu, J. T., and B. P. Mohanty (2002), Spatial averaging of Van Genuchten hydraulic parameters for steady state flow in heterogeneous soils: A numerical study, Vadose Zone J., 1, 261-272.

Zhu, J. T., and B. P. Mohanty (2003), Effective hydraulic parameters for steady state vertical flow in heterogeneous soils, Water Resour. Res., 39(8), 1227, doi:10.1029/2002WR001831.

Zhu, J., and B. P. Mohanty (2004), Soil hydraulic parameter upscaling for steady flow with root water uptake, Vadose Zone J., 3, 1464-1470.

Zhu, J., B. P. Mohanty, A. Warrick, and M. T. Van Genuchten (2004), Correspondence and upscaling of hydraulic functions for steady-state flow in heterogeneous soils, Vadose Zone J., 3, 527-533.

A. V. M. Ines, International Research Institute for Climate and Society, The Earth Institute at Columbia University, 61 Route 9W, Palisades, NY 10964, USA.

B. P. Mohanty, Department of Biological and Agricultural Engineering, Texas A\&M University, 2117 TAMU, 201 Scoates Hall, College Station, TX 77843, USA. (bmohanty@tamu.edu) 